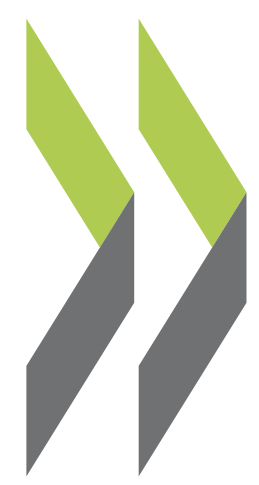

OECD Economics Department Working Papers No. 1097

\section{Capacity Needs}

in the Automobile Industry in the Short- to Medium Run
Caroline Klein, Isabell Koske 
Organisation de Coopération et de Développement Économiques

Organisation for Economic Co-operation and Development

26-Nov-2013

ECONOMICS DEPARTMENT

English - Or. English

\section{CAPACITY NEEDS IN THE AUTOMOBILE INDUSTRY IN THE SHORT- TO MEDIUM RUN}

ECONOMICS DEPARTMENT WORKING PAPERS No. 1097

By Caroline Klein and Isabell Koske

All Economics Department Working Papers are available through OECD's Internet website at http://www.oecd.org/eco/Workingpapers

JT03349288

Complete document available on OLIS in its original format

This document and any map included herein are without prejudice to the status of or sovereignty over any territory, to the delimitation of international frontiers and boundaries and to the name of any territory, city or area. 


\section{Abstract/ Résumé}

\section{Capacity needs in the automobile industry in the short- to medium run}

This paper aims at identifying which countries and regions in the world might face structural overcapacities or capacity shortfalls in the automobile industry in the near future. It discusses the main forces that are likely to shape car demand over the next several years, including GDP growth, oil prices and competitiveness. It also presents projections for car sales and production in 56 OECD and non-OECD countries, distinguishing between temporary developments related to the cycle and more persistent patterns. The paper shows that most countries might need to build capacity in the medium run, with major differences across regions though. A comparison of projected production levels in 2020 (between 125 and 130 million cars worldwide) with actual capacity in 2012 indicates that additional production capacity of around 35 to 40 million cars needs to be built over the next eight years. The countries with the biggest projected need to expand capacity over the projection period are India and China. While car demand may be sufficient to clear excess capacities in Europe as a whole in the medium run, overcapacity may persist in a few countries, in particular Italy and France. Reducing overcapacity in these countries might be difficult without substantial improvements in competitiveness.

\section{JEL classification codes: E21, L62}

Keywords: automobile industry, car sales, medium-run projections, overcapacity

\section{$* * * * * * * * * * * * *$}

\section{Besoin de capacités dans l'industrie automobile à court et moyen terme}

Ce document vise à identifier les pays dans lesquels des surplus ou des besoins de capacité dans le secteur automobile pourraient se matérialiser dans un avenir proche. Il discute les principales forces qui sont susceptibles d'influencer la demande de voitures au cours des prochaines années, notamment la croissance du PIB, les prix du pétrole et la compétitivité. Il présente également des projections pour les ventes et la production automobiles dans 56 pays de l'OCDE et non-OCDE, en distinguant les évolutions temporaires liées au cycle et les tendances plus persistantes. L'étude montre que la plupart des pays de l'OCDE pourraient avoir besoin de renforcer leurs capacités à moyen terme, avec toutefois d'importantes différences entre les régions. Une comparaison des niveaux de production projetés en 2020 (entre 125 et 130 millions de voitures dans le monde) avec la capacité observée en 2012 indique que les capacités de production devraient être accrues d'environ 35 à 40 millions au cours des huit prochaines années. Les pays ayant les plus grands besoins d'expansion sur la période de projection sont l'Inde et la Chine. Alors qu'à moyen terme la demande automobile pourrait suffire à absorber les capacités excédentaires de l'Europe dans son ensemble, des problèmes de surcapacité pourraient persister dans quelques pays, en particulier en Italie et en France. Réduire les surcapacités dans ces pays pourrait être difficile sans amélioration substantielle de la compétitivité.

\section{JEL classification codes : E21, L62}

Mots-clefs: industrie automobile, vente de voitures, projections de moyen terme, surcapacité

(C) OECD (2013)

You can copy, download or print OECD content for your own use, and you can include excerpts from OECD publications, databases and multimedia products in your own documents, presentations, blogs, websites and teaching materials, provided that suitable acknowledgment of OECD as source and copyright owner is given. All requests for commercial use and translation rights should be submitted to rights@oecd.org. 


\section{TABLE OF CONTENTS}

\section{CAPACITY NEEDS IN THE AUTOMOBILE INDUSTRY IN THE SHORT- TO MEDIUM RUN.......... 5}

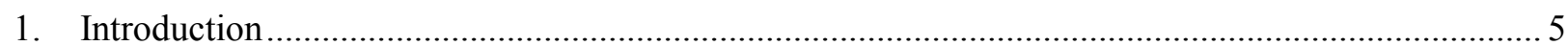

2. The automotive industry plays an important role in economic developments .................................. 7

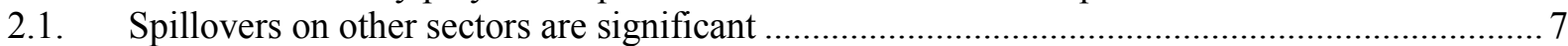

2.2. Activity in the automotive industry is strongly correlated with the business cycle .................. 8

2.3. The automotive industry is one of the sectors with high R\&D intensity ................................. 8

3. After-effects of the crisis and underlying shifts in demand affect the car industry ........................... 9

3.1. The automobile industry has not yet fully recovered from the crisis......................................

3.2. Demand is shifting from advanced to emerging countries.................................................... 10

3.3. Demand is shifting towards smaller, eco-friendly and interconnected cars.............................. 13

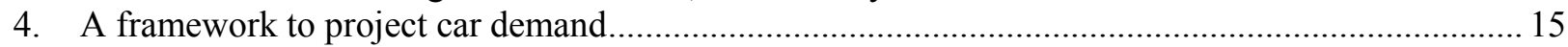

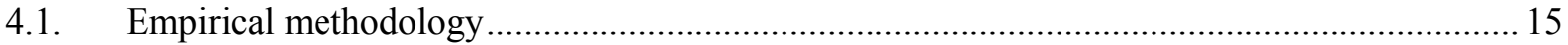

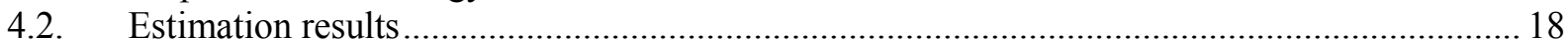

5. Capacity expansion will be required, but mostly in emerging countries ........................................ 20

5.1 Car sales growth is set to increase only marginally in the OECD over the next two years ......21

5.2 Over the medium run demand is expected to grow mainly in Asia and South America .......... 25

5.3 Only a few European countries might have overcapacities in the medium run .......................22

5.4 The results depend on the assumptions about policies and macroeconomic conditions........... 29

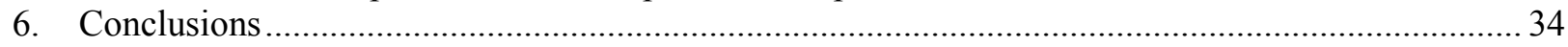

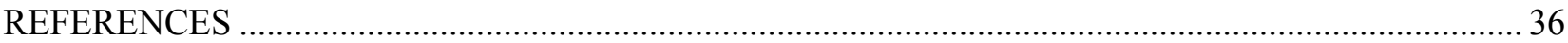

\section{Tables}

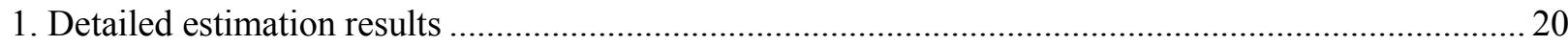

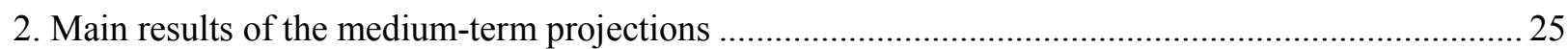

\section{Figures}

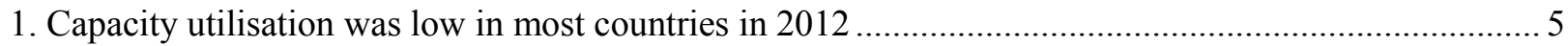

2. The economic importance of the automotive industry varies widely across countries .......................... 7

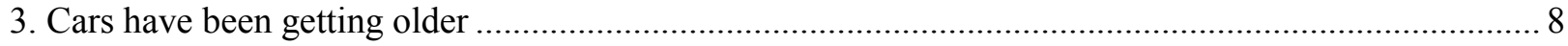

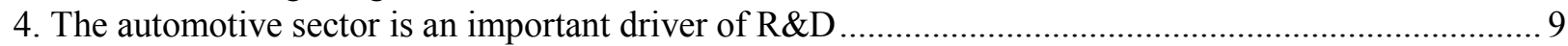

5. Car sales remain below their pre-crisis level in most OECD countries ............................................. 10

6. Emerging economies account for an ever higher share of world car demand ..................................... 11

7. China is by far the largest consumer and producer of passenger cars .............................................. 11

8. Car ownership rates are still very low in most emerging markets................................................ 12

9. Cars are for the most part manufactured in the region where they are sold ...................................... 13

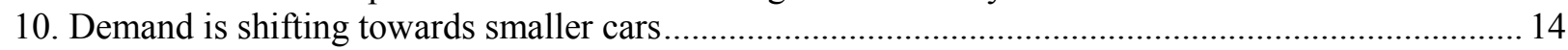

11. Manufacturers around the world are investing more heavily in green transport technologies............ 15

12. Car ownership rates are rising in income, but at a declining pace .................................................. 17

13. Estimated income elasticity decreases with the level of GDP per capita ........................................... 19

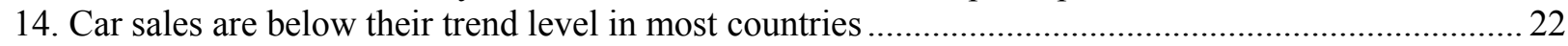

15. Capacity utilisation is unlikely to improve in Western Europe........................................................... 23

16. The cyclical situation does not fully explain overcapacity in some countries .................................24

17. Passenger car sales will grow rapidly in Asia and South America .................................................. 26

18. Production prospects depend on both domestic sales and international trade patterns ....................... 27 


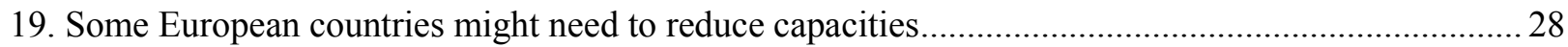

20. Comparative advantages diverge across European countries..........................................................2 29

21. The results hinge on assumptions underlying the projections ......................................................... 30

22. Capacity required to satisfy future demand is uncertain ................................................................. 30

23. Overcapacities persist in several EU countries under various scenario assumptions.......................... 31

\section{Boxes}

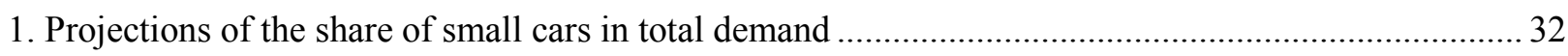

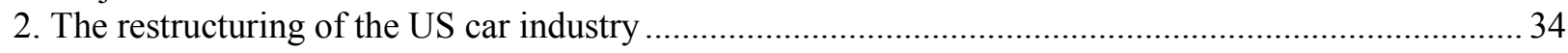




\title{
CAPACITY NEEDS IN THE AUTOMOBILE INDUSTRY IN THE SHORT- TO MEDIUM RUN
}

\author{
By \\ Caroline Klein and Isabell Koske ${ }^{1}$
}

\section{Introduction}

1. The automobile sector was severely hit by the economic crisis. Despite government support schemes, automobile production plummeted in 2008 and even in 2012 production was still $8 \%$ below its pre-crisis level in the OECD. On average across countries, capacity utilisation stood at around $70 \%$ in 2012 well below the historical average in manufacturing of around $80 \%$ (Figure 1). ${ }^{2}$ The situation is particularly severe in several European countries, where manufacturers have had to close assembly plants with consequent job losses.

Figure 1. Capacity utilisation was low in most countries in 2012

Current and potential production in million units ${ }^{1}$

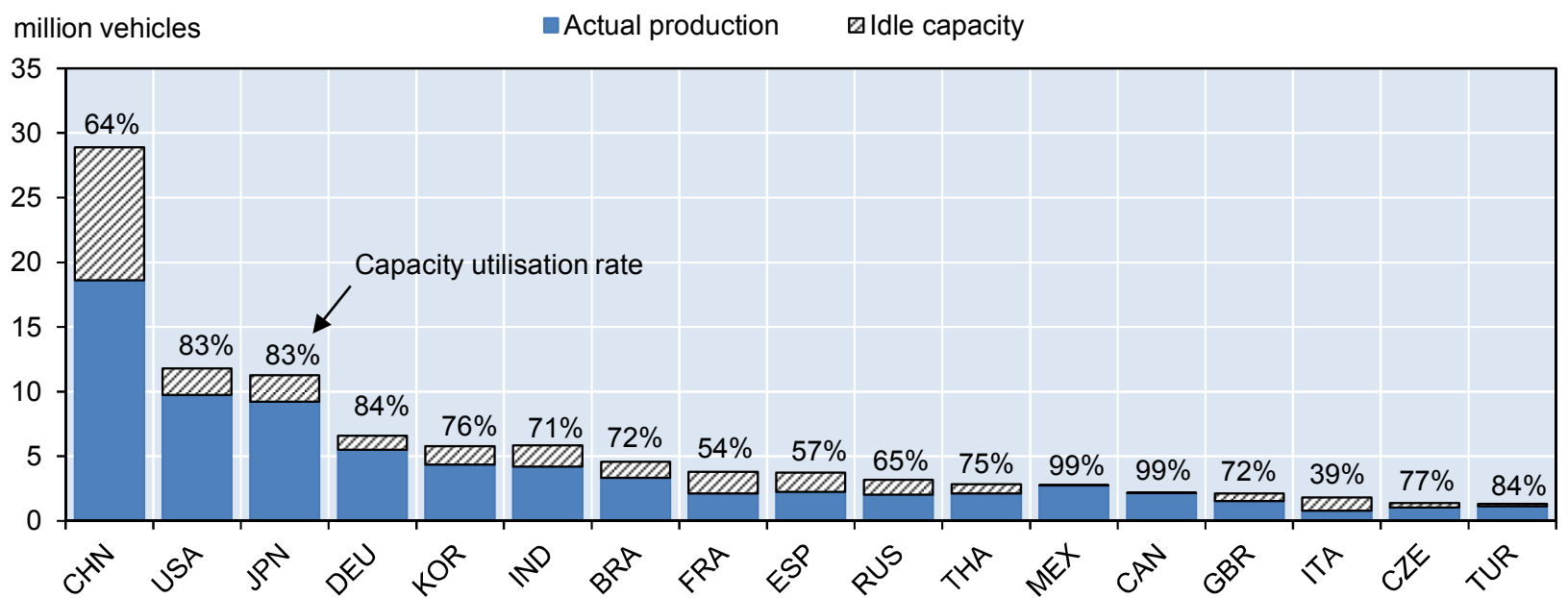

Note: Capacity utilisation is measured as current production as a percentage of potential production in 2012.

Source: LMC Automotive database.

1. The authors are members of the OECD Economics Department. They would like to thank Jørgen Elmeskov, Jean-Luc Schneider, Alain de Serres, Isabelle Wanner, Richard Herd, Sonia Araujo, and Paul O'Brien for their helpful comments and suggestions, as well as Caroline Abettan for excellent technical support. The opinions expressed in this paper are those of the authors' alone and do not necessarily represent those of the OECD or its member countries.

2. In the US, the average capacity utilisation rate in the automobile and light duty motor vehicle industry between 1990 and 2007 amounts to around 80\%. The average capacity utilisation rate on the same time period in the manufacturing sector in the OECD also stands at around $80 \%$. 
2. Prospects for car sales and production depend on how much of the decline in recent years was due to cyclical factors as opposed to more fundamental drivers such as market saturation and changing demand patterns (e.g. less frequent replacements of old cars as a result of better quality). To address this issue, the medium-term prospects for car sales and production in 56 OECD and non-OECD countries have been assessed, distinguishing between temporary developments related to the cycle and more persistent patterns. This paper aims at identifying which countries might face structural overcapacities or capacity shortfalls in the near future. It also assesses the factors that drive future developments of car sales, including GDP growth, oil prices and competitiveness. In tackling these issues, the focus is on the production of passenger cars and light commercial vehicles, i.e. the assembly stage of car production. Heavy commercial vehicles as well as components and parts are excluded from the analysis. ${ }^{3}$

3. The following main conclusions emerge from the analysis:

- Projections of future car sales suggest that growth will mostly take place in emerging markets. The growth rate until 2020 is projected to average 3\% per year for OECD countries and $9 \%$ per year for the BRIICS.

- A comparison of projected production levels in 2020 (between 125 and 130 million cars worldwide) with actual capacity in 2012 indicates that additional production capacity of around 35 to 40 million cars needs to be built over the next 8 years. The countries with the biggest need to expand capacity in the medium term are India and China.

- As cars are mostly traded within regions, car assembly plants in European countries might hardly benefit from the strong growth in emerging markets. Hence, while car demand may be sufficient to clear excess capacities in Europe as a whole by 2020, overcapacity may persist in a few countries, in particular Italy and France. Substantial gains in competitiveness and export market shares might be needed to reduce overcapacity in these countries.

- There is a large degree of uncertainty surrounding these projections. Notably, they do not account for policy changes to mitigate greenhouse gas and other pollution emissions as well as congestion, which could significantly reduce the increase in demand, particularly in emerging markets.

4. The remainder of this paper is structured as follows: Section 2 puts in perspective the importance of the car sector in the overall economy across countries. Section 3 discusses the factors that shape developments in the industry over the short to medium run. Section 4 presents the empirical methodology which is used subsequently in Section 5 to assess the short- and medium-term prospects for car demand and the implications for capacity utilisation. Finally, Section 6 concludes with some policy implications.

3. This working paper focuses on the automobile sector i.e. the manufacturing of light motor vehicles. The concepts of "automotive sector" and "transport equipment sector" are also used in the paper. The automotive sector includes manufacturing of motor vehicles, trailers and semi-trailers, the manufacturing of bodies (coachwork) for motor vehicles and the manufacturing of parts and accessories for motor vehicles and their engines. The transport equipment sector refers more broadly to the production of equipment for transporting people and goods (including motor vehicles, but also railway vehicles, aircraft, ships). 


\section{The automotive industry plays an important role in economic developments}

\subsection{Spillovers on other sectors are significant}

5. While the decline in sales and the built-up of overcapacity have benefited consumers by weighing on car prices, they risk undermining the long-run viability of the automotive industry in countries where they are most sizeable. The extent of overcapacities currently observed in some countries raises concerns about the prospects of a severe restructuring of the sector. Such restructuring could have far-reaching implications due to the economic importance of the sector. The direct share of the automotive sector in total value added and employment is relatively small. Even in countries with a large automotive industry such as Germany and the Czech Republic, the manufacturing of motor vehicles, trailers and semi-trailers as well as bodies and parts and accessories for motor vehicles and their engines does not account for more than $4 \%$ of value added and $2 \%$ of employment (Figure 2). However, there are important spillovers on other sectors (e.g. steel, chemical, electronic components and textile). Estimates of these spillovers put the multiplier at 3 on average in G7 countries, i.e. a dollar increase in value added in the automotive sector generates 3 dollars of value added economy-wide, a level that is close to the top of what is observed for other sectors (Haugh et al., 2010).

Figure 2. The economic importance of the automotive industry varies widely across countries

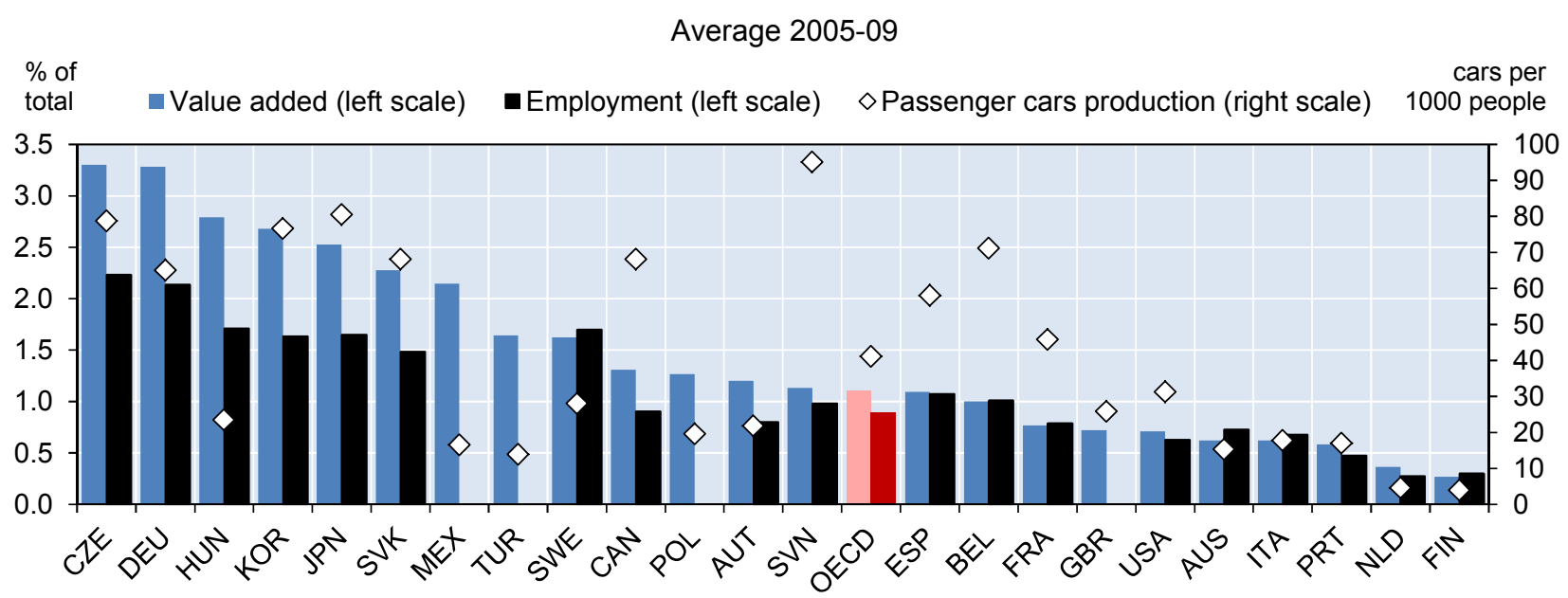

Note: Value added and employment data refer to ISIC Rev. 3.1 class 34 and hence include the manufacturing of motor vehicles, trailers and semi-trailers, the manufacturing of bodies (coachwork) for motor vehicles and the manufacturing of parts and accessories for motor vehicles and their engines.

Source: OECD STAN database, OECD Economic Outlook database, LMC Automotive database.

6. The multiplier varies across countries as it depends on the structure of the supply chains, in particular the import content of the intermediate inputs to the sector. An INSEE study estimates multipliers at 4.1 for Japan, 3.6 for the USA, 3.1 for France, 2.9 for the United Kingdom, and 2.8 for Spain (INSEE, 2009). The multiplier is stronger for countries with lower foreign value-added content in car production. The United States and Japan are amongst the countries with the lowest foreign value-added content of transport equipment exports in the OECD, reflecting the countries' size and the predominance of domestic value chains with a diversified domestic supplier base (OECD, 2013). By contrast, in large EU economies, the foreign value-added content of transport equipment exports is relatively large (around $20 \%$ to $40 \%$ ). 


\subsection{Activity in the automotive industry is strongly correlated with the business cycle}

7. Activity in the automotive industry is strongly linked to the overall business cycle as demand for cars is highly sensitive to economic conditions. Cars are durable goods whose consumption can adapt to the economic situation, e.g. purchases can be delayed during downturns or when economic prospects are uncertain. High uncertainty about future economic developments increases the option value of postponing spending and thus weighs on car demand (Hassler, 2001). Data suggest that households indeed delayed the replacement of cars during the crisis. The average age of car fleets in European countries rose over the past few years, with the trend accelerating after 2007 (Figure 3). According to Polk experts, the average age of cars in the United States reached a record high at 11.4 years mid-2013. The comparatively high volatility of the sector implies that the industry can, at times, make a large contribution to aggregate fluctuations in economy-wide activity (Haugh et al., 2010). In particular during and after the crisis, the contribution of the automobile sector to GDP growth was quite large. For instance, in the United States, it amounted to 0.5 percentage point in 2010 and to 0.3 percentage point in 2011 and 2012. In France, the automobile industry contributed 0.1 percentage point to GDP growth in 2010. Conversely, car demand influences the business cycle and the strong inter-linkages between the car industry and other sectors of the economy amplify this link.

Figure 3. Cars have been getting older

Percentage share of different age segments in total car fleet, cross-country average

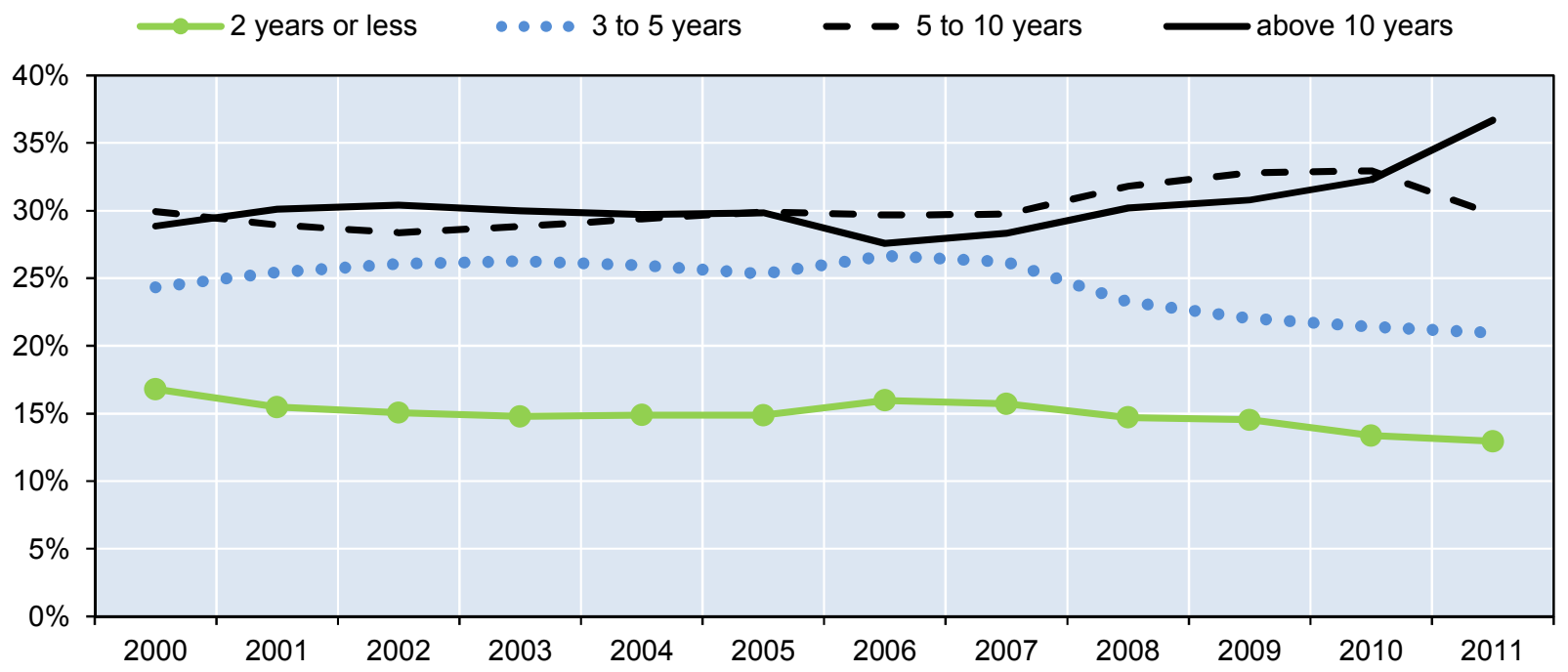

Note: Percentage shares of different age segments in total car fleet of 16 European countries (i.e. Austria, Belgium, Czech Republic, Estonia, Finland, Germany, Hungary, Ireland, Italy, Netherlands, Norway, Slovenia, Spain, Sweden, Switzerland, and the United Kingdom). Data were not available for 2011 for Austria, Czech Republic, Hungary, Ireland, Sweden, and the United Kingdom. For these countries, the age composition of car fleet is assumed to remain the same in 2011 as in 2010.

Source: UNECE Transport Division database.

\subsection{The automotive industry is one of the sectors with high $R \& D$ intensity}

8. The industry is also an important source of innovation, as indicated by its high share in total R\&D spending. For example, in Czech Republic, Sweden, France and Japan, the sector accounts for more than $15 \%$ of all R\&D spending and in Germany, its share even exceeds $30 \%$ (Figure 4). In principle, this could mean that a shrinking of the sector in those countries could have important repercussions on a country's innovative capacity, with negative implications for long-run GDP per capita growth. In practice, 
however, resources devoted to $R \& D$ are to some extent fungible across the economy - at least over the longer term. Moreover, since most firms operating in the sector have production capacities in several countries and regions of the world, either directly or through business alliances, they may maintain important research and development facilities in their home country even if production were to decline.

Figure 4. The automotive sector is an important driver of R\&D

Share of the automotive industry in total R\&D spending, selected OECD countries, average 2005-09

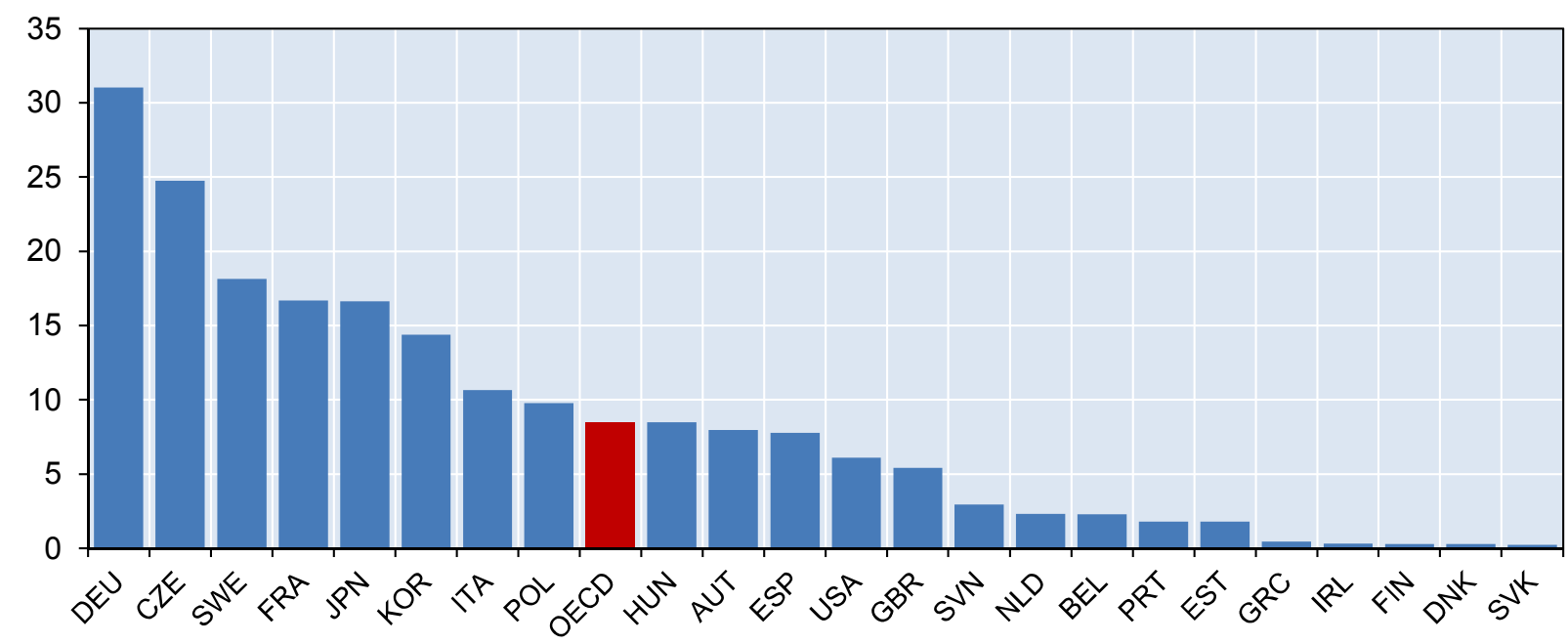

Source: OECD, STAN database.

\section{After-effects of the crisis and underlying shifts in demand affect the car industry}

9. The automobile industry was hit hard by the recent economic crisis, with car sales falling sharply across the OECD. While demand has recovered in several countries, including the United States, other countries, in particular in Europe, are still struggling with low demand. Beyond the hurdles related to the crisis, the automobile industry faces strategic and technological challenges. Car manufacturers need to adjust to changing demand patterns, in particular a shift in demand towards emerging markets, notably in Asia, as well as smaller cars, more environmentally friendly cars (i.e. cars with more efficient combustion engines, hybrid and electric powertrains) and interconnected cars (i.e. cars connected though internet and local area networks). This section briefly discusses these trends and the challenges they pose to automobile producers.

\subsection{The automobile industry has not yet fully recovered from the crisis}

10. Following the recession-induced decline, new car sales bounced back in many countries in $2009 / 10$, coinciding with the initial recovery in economic activity and reflecting the impact of the various schemes (including widespread car scrapping schemes) put in place by governments to encourage car purchases. ${ }^{4}$ Since then, the picture has been rather diverse, reflecting cross-country differences in economic performance after the crisis, notably income growth. While the steady recovery in household purchasing power in the United States has boosted car demand, economic stagnation and high unemployment have weighed on consumers' income and, hence, car sales in Europe. As a result, sales in European countries at

4. For instance, the "cash for clunkers" programme in the US had a positive impact on sales in 2009, estimated at 39500 units and contributing 1.45\% to GDP growth in 2009Q3 (Cooper et al., 2010). 
the end of 2012 were about $20 \%$ below their pre-crisis level, with the gap varying from less than 5\% in Germany and $15 \%$ in the United Kingdom to $50 \%$ or more in Italy, Portugal and Spain. In Japan, car demand dropped significantly after the tsunami in 2011, but then returned to its pre-crisis level in the course of 2012. In emerging countries, growth slowed somewhat in 2008/09, but remained strong (Figure 5).

Figure 5. Car sales remain below their pre-crisis level in most OECD countries

Car and light duty vehicles by region, millions of units

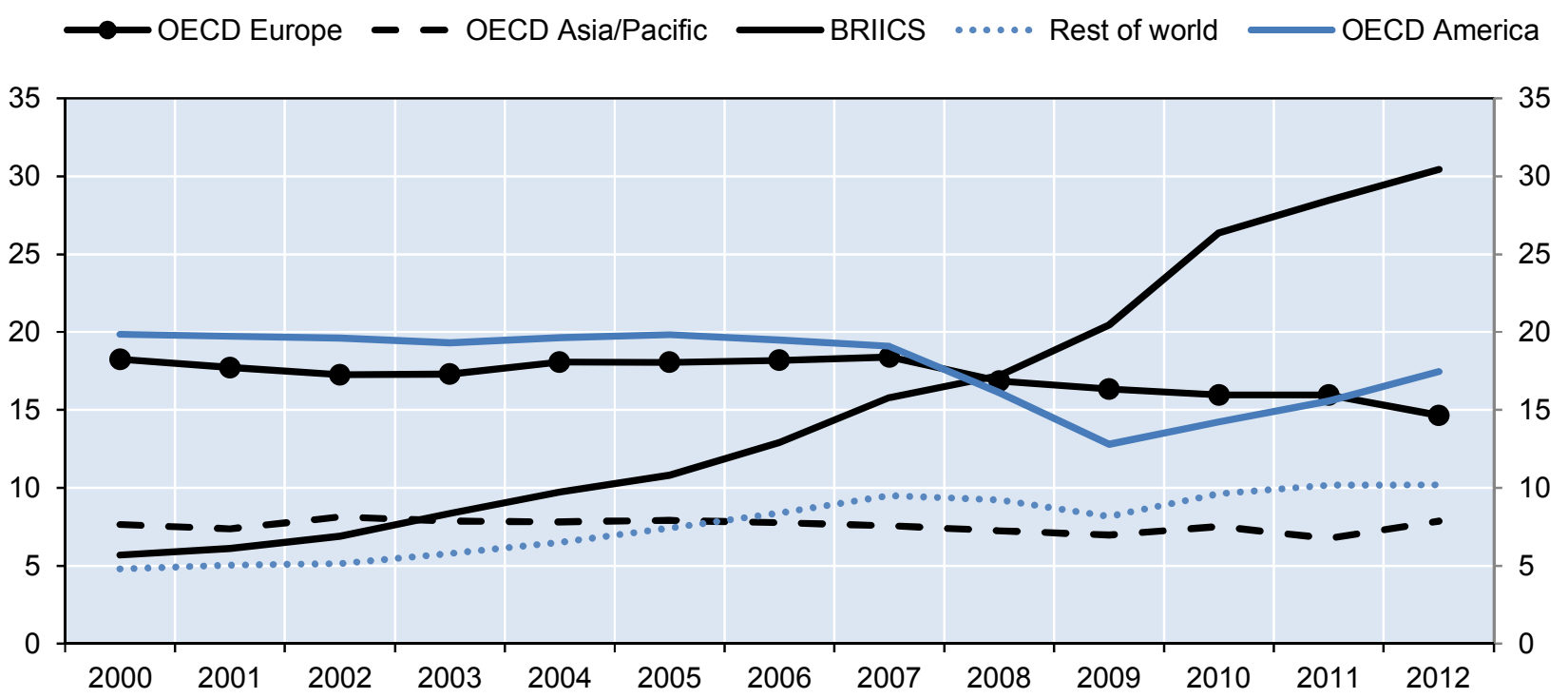

Source: LMC Automotive.

\subsection{Demand is shifting from advanced to emerging countries}

11. The automobile industry is also facing important challenges that go beyond the recent crisis and have a more medium- to long-term bearing on the sector. Most notably, demand is shifting from advanced to emerging economies. While OECD countries still accounted for $80 \%$ of world passenger car sales in 2000 , their share had dropped to around $50 \%$ by 2012. The share of BRIICS in car sales more than tripled over the same period, reaching almost $40 \%$ (Figure 6). With a $24 \%$ share of world sales, China is the largest market for passenger cars, well ahead of the European Union and the United States with 17\% and 18\% respectively (Figure 7). Between 2000 and 2012, passenger car sales in the BRIICS more than quintupled, driven by rapidly rising incomes (the average annual growth rate was $15 \%$ ). China and India account for around $70 \%$ and $10 \%$ of this increase respectively. With car ownership rates still low by international standards (Figure 8), sales are set to keep growing at a fast pace in the foreseeable future in emerging countries, even though potentially rising fuel prices and regulatory restrictions on car ownership to cope with congestion and environmental problems are likely to dampen growth somewhat. In China, for instance, four cities (Beijing, Shanghai, Guiyang and Guangzhou) currently operate restrictions on the number of license plates and two more (Wenzhou and Nanjiing) will follow soon (KPMG, 2013). ${ }^{5}$

5. In Shanghai, the licence plates are auctioned. Their cost has recently reached USD 14,000 a level that largely exceeds the price of a small car in China. Beijing and Guiyang use a lottery system. In Beijing, one in 80 applicants obtained a licence plate in July 2013. Guangzhou auctions 40\% of the plates and grants the rest via a lottery. 
According to more recent statements by the China Association of Automobile manufactures, eight cities are likely to introduce restrictions, reducing annual sales by $2 \%$. Other analysts point out that the negative impact of these restrictions should be limited as sales might be mainly driven by demand from smaller cities and Central western regions (Nielsen, 2013).

Figure 6. Emerging economies account for an ever higher share of world car demand Share in total passenger car sales in per cent

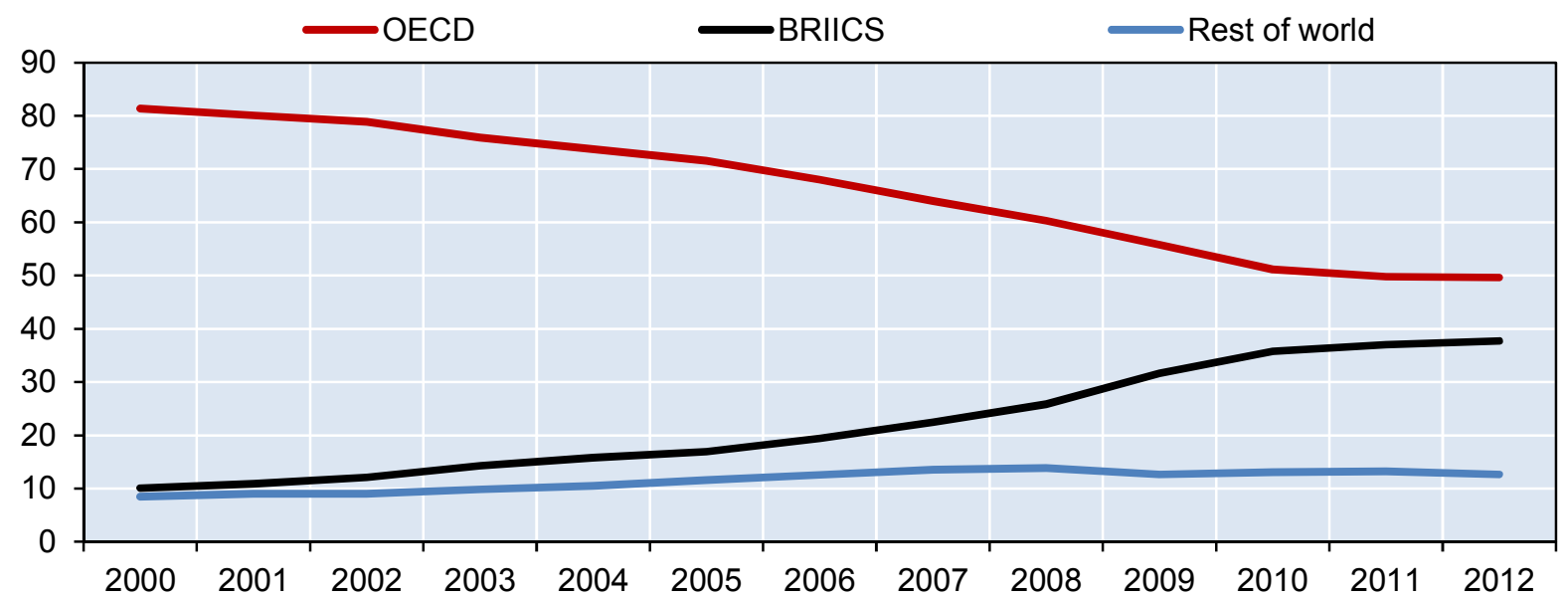

Source: Authors' calculations based on sales database by LMC Automotive.

Figure 7. China is by far the largest consumer and producer of passenger cars

Composition of sales, 2012

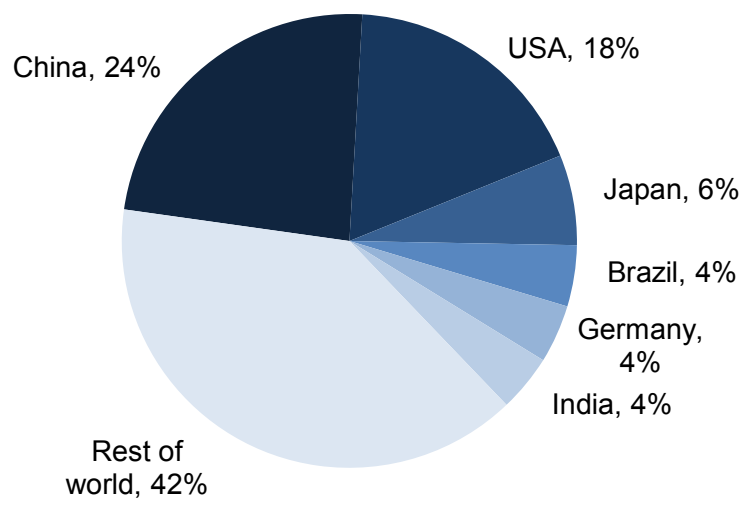

Composition of production, 2012

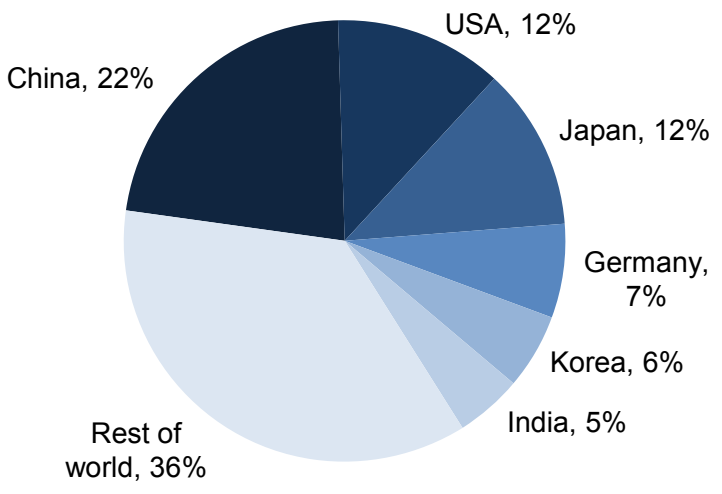

Source: Authors' calculations based on sales database by LMC Automotive.

12. At the same time, car sales in the OECD have declined over the past decade and stand $13 \%$ below their 2000 level. While falling incomes during the recession have clearly contributed to this, growth had been subdued even prior to the crisis in many OECD countries, owing to market saturation (Figure 5), rising fuel prices, and low population growth. As the same forces are likely to be acting going forward, sales growth in many advanced countries might remain sluggish. Moreover, growing pressures to abate pollution emissions, not least to mitigate climate change, are raising the costs of owning a car (e.g. through higher taxes and congestion charges) while reducing the benefits (e.g. through urban driving restrictions). As an alternative, consumers may increasingly resort to public transportation or to car sharing 
arrangements, which offer mobility at a low cost, albeit with reduced comfort and flexibility (Capgemini, 2013). ${ }^{6}$

Figure 8. Car ownership rates are still very low in most emerging markets

Passenger cars per 1000 people, 2010 or latest available year

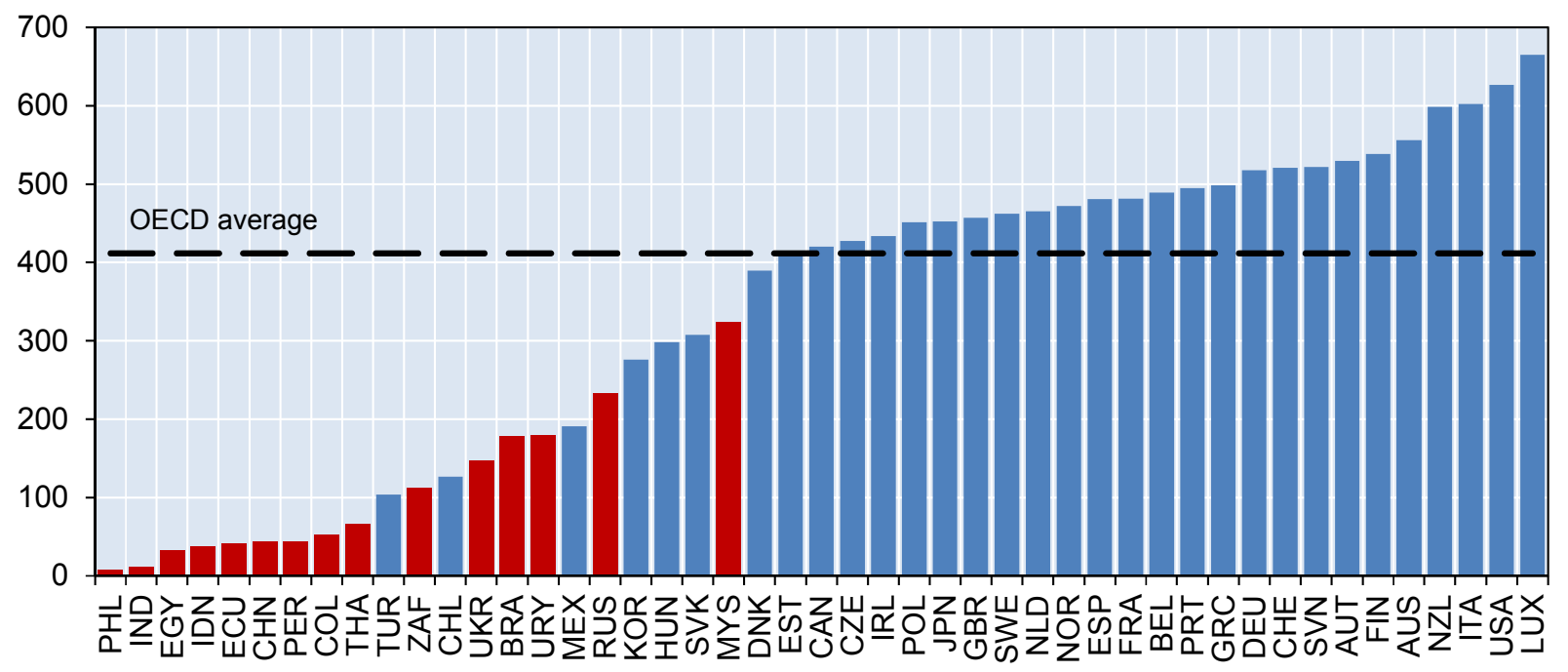

Source: World Bank, World Development Indicators database.

13. The shift in demand from OECD to emerging markets has important implications for automobile producers. While in principle, cars could simply be exported from declining to growing markets, cars are typically assembled in the region where they are sold, not least due to relatively high transportation costs and trade barriers (Figure 9). In 2011, only around 11\% of all produced passenger cars were traded between North America, Europe and South-East-Asia. High import duties in several emerging markets further impede trade. In China, for example, a $25 \%$ import tariff applies to cars and the import penetration ratio was only around 5\% in 2011 compared with around $45 \%$ in the United States. While many manufacturers from OECD countries already produce a large proportion of their cars in emerging markets (for example, in 2012, Volkswagen and GM produced around 40\% of their cars in non-OECD countries), they will likely need to further increase capacities in these countries going forward in order to maintain their market shares. At the same time, producers from emerging markets are increasingly penetrating OECD countries through car plants in Europe and North America, thus raising competitive pressures there.

6. In a recent consumer survey, $20 \%$ of respondents in mature markets and $57 \%$ of respondents in emerging markets said that they are likely to consider car sharing as an alternative to car ownership. In particular younger consumers consider car sharing programmes as a viable alternative. Half of those aged 18 to 34 said that they would consider it as an alternative to buying (Capgemini, 2013). 
Figure 9. Cars are for the most part manufactured in the region where they are sold

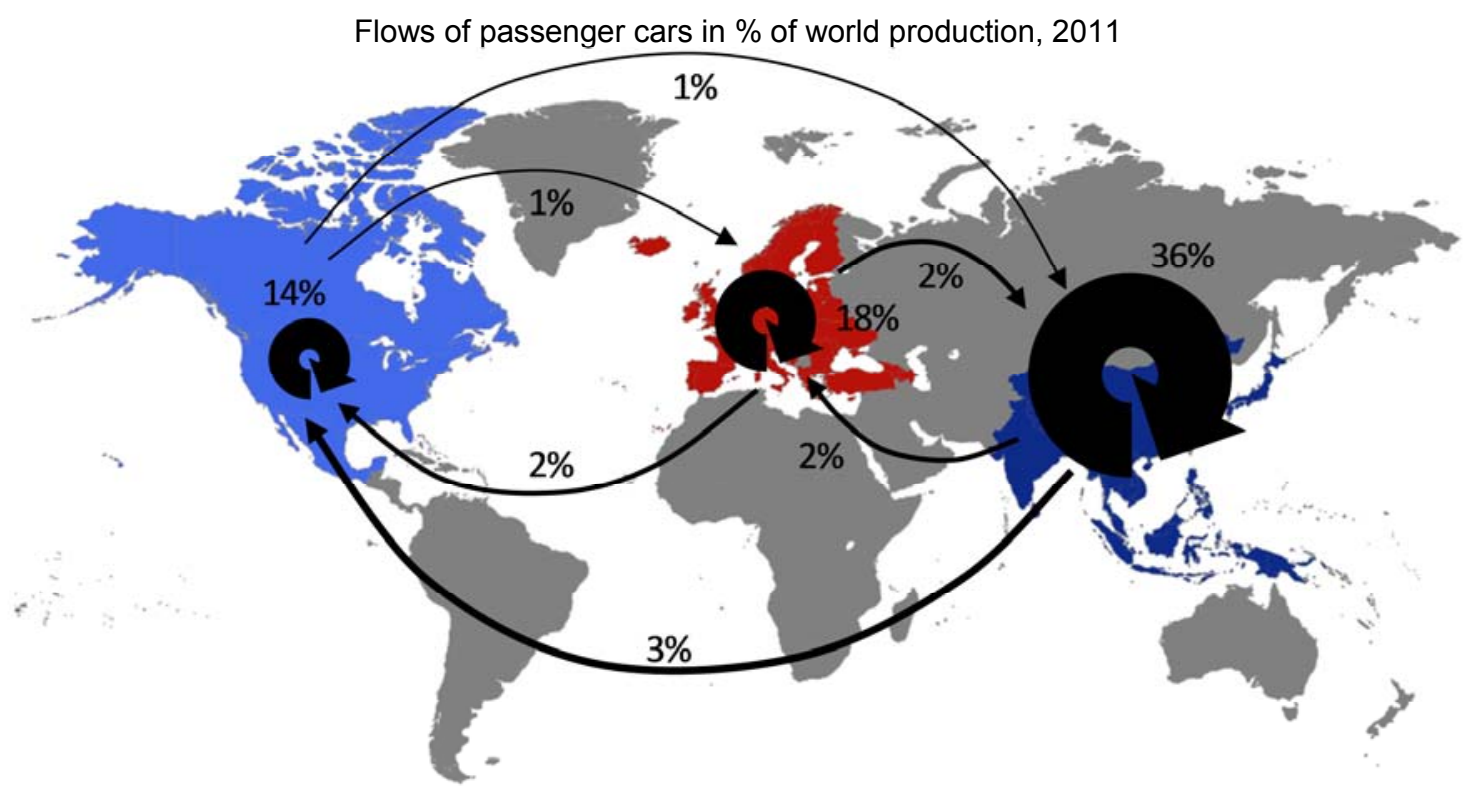

Source: Authors' calculations based on UN Comtrade and sales database by LMC Automotive.

\subsection{Demand is shifting towards smaller, eco-friendly and interconnected cars}

14. Another important trend is a shift in demand towards smaller and more fuel-efficient cars. Between 2000 and 2012, the share of basic, compact and sub-compact vehicles in total world car sales increased steadily, from $42 \%$ to $53 \%$ (Figure 10). At the same time, the shares of midsized and multi-purpose vehicles as well as large, luxury and sports vehicles went down, from $17 \%$ to $11 \%$ and from $9 \%$ to $4 \%$, respectively. This development does not reflect a composition effect, whereby the share of non-OECD countries - where lower purchasing power means that a sizeable proportion of customers are buying smaller, more basic models - in total world car sales went up. In OECD countries as well customer preferences are shifting towards smaller cars. ${ }^{7}$ Small cars account for an equivalent share of total sales in the OECD and in the BRIICS. Several factors could be behind this trend, including the strong increase in oil prices over the past two decades, public perception that small cars consume less fuel than their larger counterparts, as well as improvements in vehicle design which limit the loss in comfort from switching to a smaller car. ${ }^{8}$ Still, there are important cross-country differences in purchasing behaviour. In European countries small cars are much more common than in the US, where SUVs and pickups still dominate.

7. Between 2000 and 2012, the share of basic, compact and sub-compact vehicles in total car sales rose from $64 \%$ to $69 \%$ in OECD Europe, from $52 \%$ to $62 \%$ in OECD Asia/Pacific and from $21 \%$ to $35 \%$ in North America. In 2011, half of the respondents in a consumer survey in the United States, the United Kingdom, France and Germany said that they would likely purchase a smaller/lower-cost car, up from $35 \%$ a year earlier (Capgemini, 2011).

8. The price of gasoline increased from 80 cents per litre in 2000, on average across OECD countries, to about 1.9 USD per litre in 2011. The perception that small cars consume less fuel than their larger counterparts is not entirely accurate, some mid-sized cars being more fuel efficient than many small ones. 
Figure 10. Demand is shifting towards smaller cars

Shares of specific category in total sales, $2000-12$

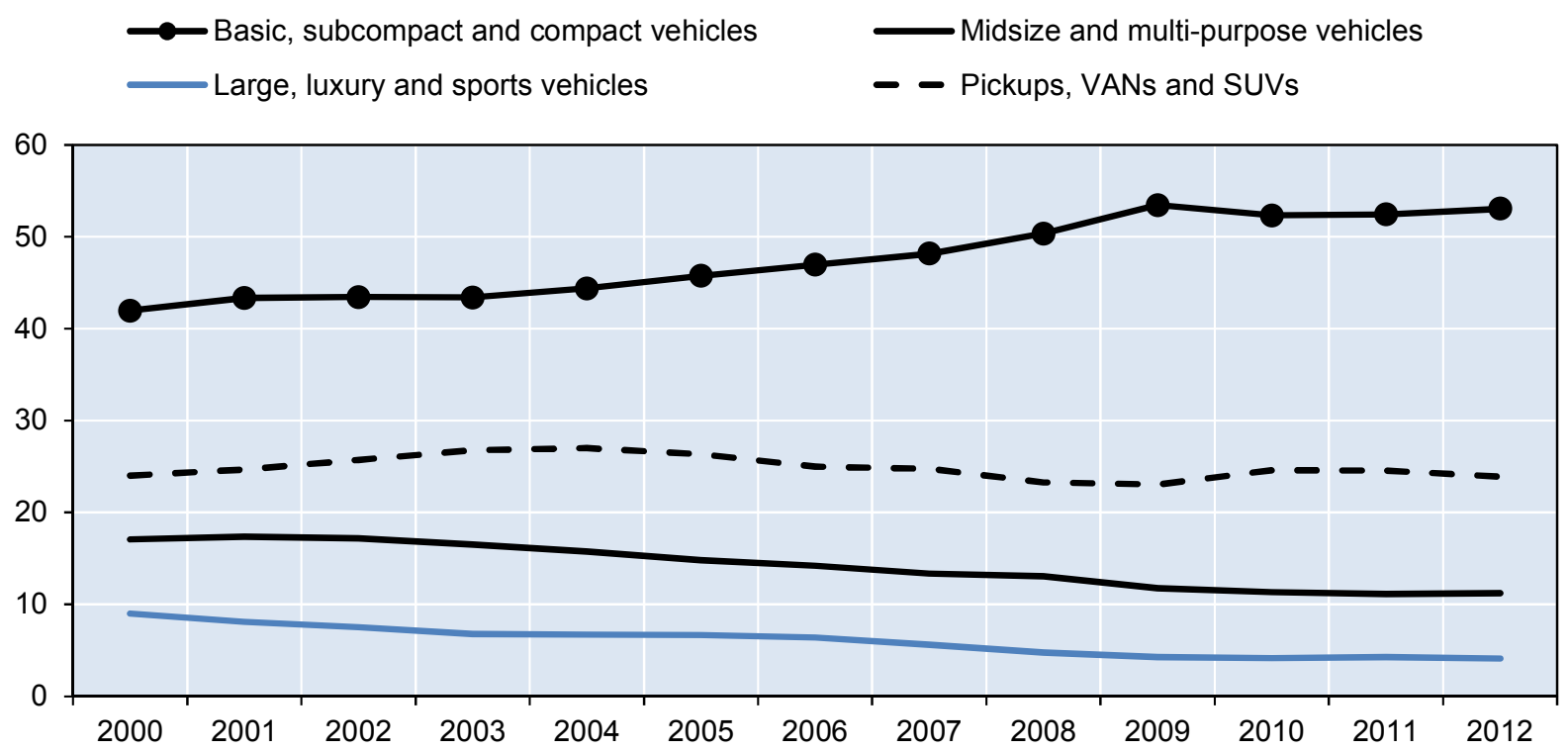

Source: Authors' calculations based on sales database by LMC Automotive.

15. Pressures on governments around the world to better protect the environment and fight pollution and climate change require further reductions in greenhouse gas and other emissions also in the transport sector. Associated fuel efficiency and emission targets such as CAFE in the United States, euro6 in the European Union, JCO8 in Japan or Bharat in India is leading to a shift in demand towards cars with more efficient combustion engines, hybrid or electric powertrains as well as lighter and more fuel-efficient vehicle designs. The rising demand for greener transport solutions is reflected in innovative activity, with patent applications in related technology fields increasing rapidly over the past decade, in particular in Japan and Korea (Figure 11). According to a survey by KPMG (2013), manufacturers around the world are still focusing their R\&D on the downsizing of international combustion engines and the development and improvement of plug-in hybrids, while electric and hybrid powertrains are unlikely to take over as the leading technology before the 2020 s.

16. Next to the electrification of the powertrain, the introduction of vehicle communications might be the second important development in automotive technology currently underway (e.g. technology enabling vehicles to communicate with the roadway via internet and allowing for intelligent navigation). With customers increasingly demanding these features (in a recent consumer survey, $11 \%$ of respondents said that they already use connected car services and $27 \%$ said that the next car they purchase would have such services; Capgemini, 2013), it is a challenge for automobile producers to keep pace with technological advances to maintain or expand market shares. Also, the development of smart cars could bring into the market new players (e.g. Google) getting into car manufacturing from another established high-tech business. Electronics firms are engaging more heavily in the market and automobile suppliers may increasingly need to form flexible partnerships with these companies in order to keep their technological edge and meet changing customer demands. 
Figure 11. Manufacturers around the world are investing more heavily in green transport technologies Patent applications filed under the Patent Cooperation Treaty (ratio to trillion 2005 GDP PPP)

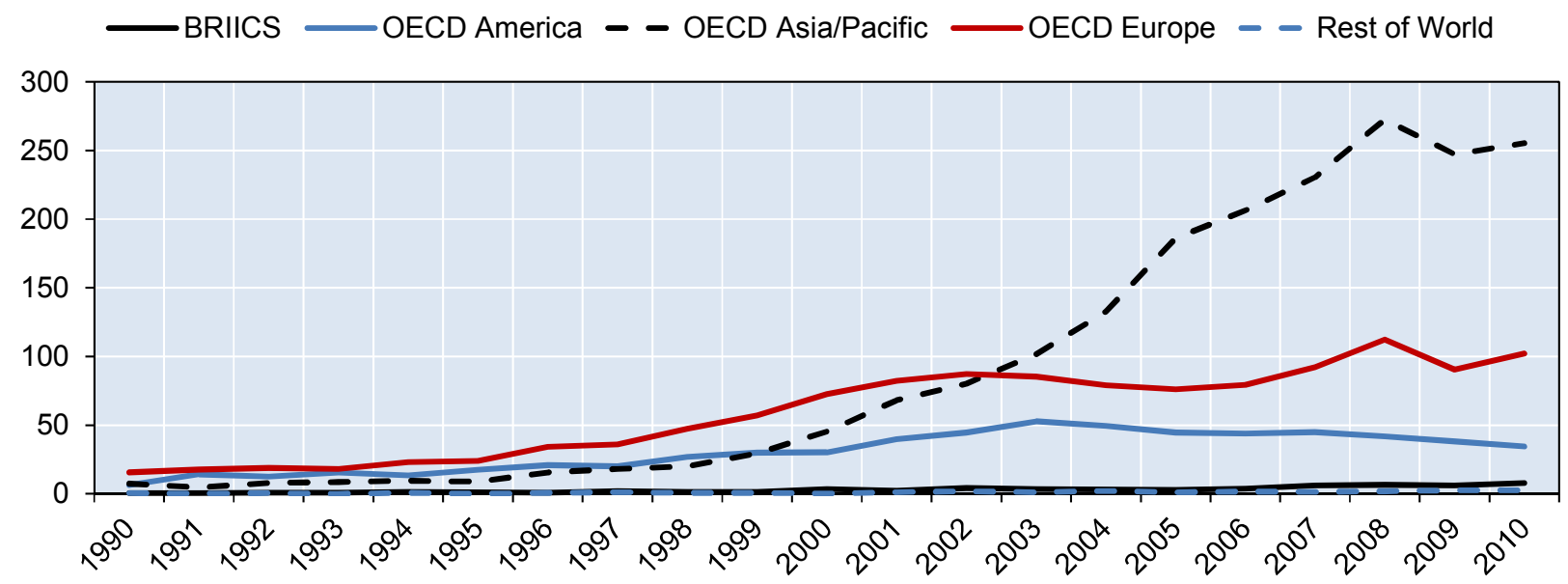

Note: Sum over five technology areas: fuel cells, fuel efficiency-improving vehicle designs, technologies for hybrid propulsion, technologies for propulsion using electric powertrains and technologies for propulsion using internal combustion engines.

Source: OECD, Patent database.

\section{A framework to project car demand}

17. The persistence of overcapacities that many OECD countries are currently facing will strongly depend on two factors, $i$ ) the extent to which current overcapacities are due to cyclical as opposed to structural factors and $\mathrm{ii}$ ) the ability of car producers in different countries to respond to the challenges raised by the major longer-term shifts in the industry landscape discussed above. This section presents an empirical framework to project future car demand which will be used in the subsequent section to assess the outlook for capacity utilisation at the country, regional and global level.

\subsection{Empirical methodology}

18. To assess the future prospects for car demand, an equation is estimated for a panel of 56 advanced and emerging market countries that links car sales to GDP per capita, squared GDP per capita (to account for the non-linear relationship between car ownership and GDP per capita), population, the unemployment rate, real oil prices and real interest rates. ${ }^{9}$ This set of explanatory variables is motivated by the following considerations:

9. Countries covered are Argentina, Australia, Austria, Belgium, Bosnia Herzegovina, Brazil, Bulgaria, Canada, Chile, China, Colombia, Croatia, Czech Republic, Denmark, Ecuador, Egypt, Estonia, Finland, France, Germany, Greece, Hungary, India, Indonesia, Iran, Ireland, Italy, Japan, Korea, Latvia, Lithuania, Luxembourg, Macedonia, Malaysia, Mexico, Netherlands, New Zealand, Norway, Peru, Philippines, Poland, Portugal, Romania, Russia, Slovakia, Slovenia, South Africa, Spain, Sweden, Switzerland, Thailand, Turkey, Ukraine, United Kingdom, United States and Uruguay. 
- The empirical analysis focuses on car sales and not on car ownership rates because of lower availability of data for the latter. ${ }^{10}$ Also, estimating car demand from car ownership rates requires making additional assumptions that have an impact on the results. ${ }^{11}$

- Car ownership - and ultimately car sales - is closely linked to the income level but in a non-linear fashion (Figure 12). At low levels of income, the car ownership rate does not depend much on income because households cannot afford a car. Car ownership generally starts to increase significantly with income only once average income exceeds a threshold estimated at around USD 5000 by Chamon et al. (2010). Above this threshold, car ownership rises with income but at a declining pace as markets are progressively saturated. Car ownership also depends on other socio-economic and country-specific factors, such as the availability of alternative transport means, the quality and size of road infrastructure, the degree of urbanisation, and the age structure of the population.

- Car sales depend on the scrapping rate of the existing car fleet, which is determined by various factors, including the age distribution of the car fleet, credit conditions, the level of oil prices, the relative price of cars, and public policies affecting consumer behaviour. The scrapping rate is likely to increase in countries where the age distribution of the car fleet is skewed towards old cars. Credit conditions determine the capacity of consumers to purchase a car since most car purchases are credit-financed (in France, for instance, $75 \%$ of cars were credit-financed in 2010). In the United States, loose credit conditions and the availability of sub-prime loans appear to have temporarily boosted car demand before 2008 (Smith and Chen, 2009).

- Higher oil prices tend to be associated with lower car sales as higher oil prices reduce household real disposable income and raise the cost of car use. Car demand is quite responsive to oil prices, with the short-term impact of oil price shocks on car sales higher than for other consumption goods (Edelstein and Kilian, 2009; Hugues et al., 2009). Studies estimate the short-run elasticity at around -0.5 to -0.7 (Edelstein and Kilian, 2009).

10. Car ownership rates were available until 2009 for most countries, while data on car sales were available until 2012.

11. The level of sales could be obtained from car ownership rates by making an assumption on the car scrapping rate. The results are quite sensitive to this assumption (Haugh et al., 2010). 


\section{Figure 12. Car ownership rates are rising in income, but at a declining pace}

motor vehicles per 1000 people

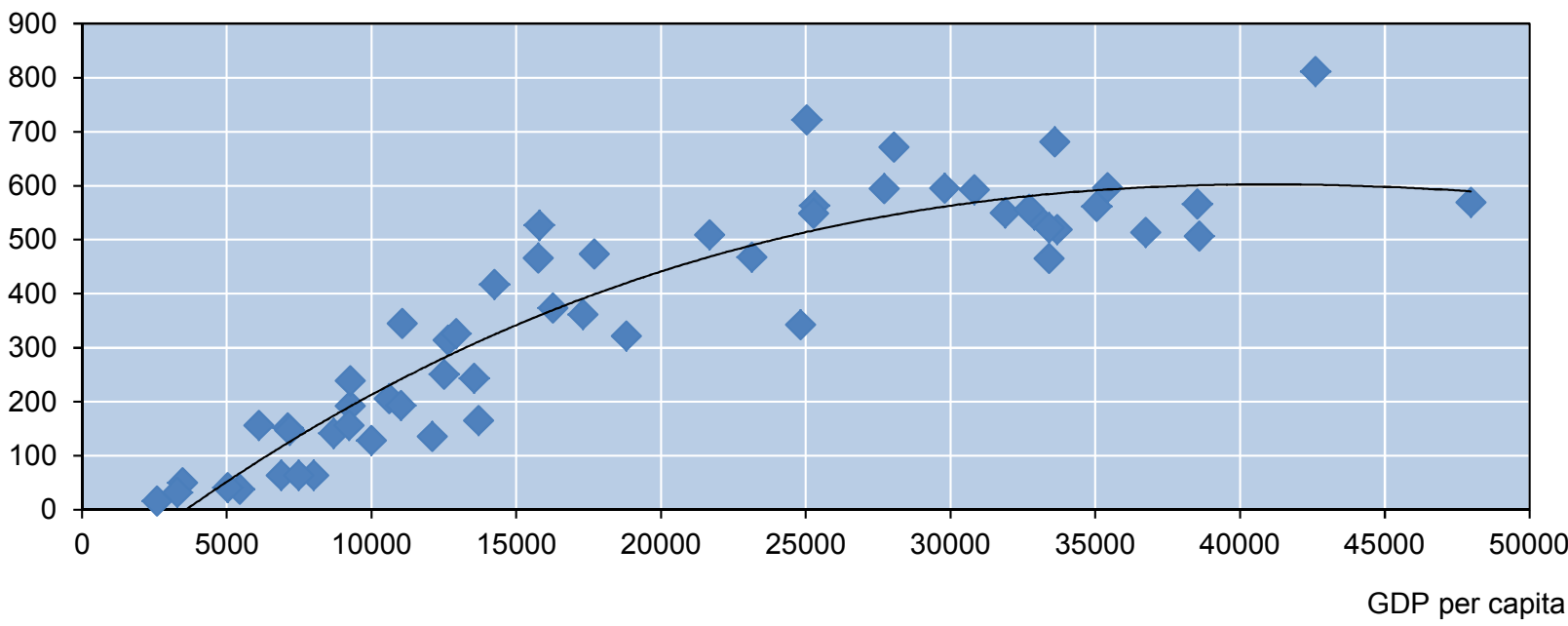

Source: World Bank, World Development Indicators database.

19. The empirical specification incorporates short-run dynamics to capture temporary deviations from the long-run relationship. Indicators for the level of urbanisation, the age structure of the population, the availability of rail and road infrastructure were also added in the specification. ${ }^{12}$ Specifically, the estimated specification takes the following form:

$$
\begin{aligned}
\Delta S_{i, t} & =\propto\left(S_{i, t-1}-\beta_{O I L} O_{I L} L_{i, t-1}-\beta_{Y} Y_{i, t-1}-\beta_{Y 2} Y_{i, t-1}{ }^{2}-\beta_{P O P} P O P_{i, t-1}-\beta_{R I S} R I S\right)-\beta_{i} \\
& +\sum_{j=1}^{2} \gamma_{S}^{j} \Delta S_{i, t-j}+\sum_{j=1}^{2} \gamma_{O I L}^{j} \Delta O I L_{i, t-j}+\sum_{j=1}^{2} \gamma_{Y}^{j} \Delta Y_{i, t-j}+\sum_{j=1}^{2} \gamma_{p o p}^{j} \Delta P O P_{i, t-j} \\
& +\sum_{j=1}^{2} \gamma_{r i s}^{j} \Delta R I S_{i, t-j}+\sum_{j=1}^{2} \gamma_{x}^{j} X_{i, t-j}
\end{aligned}
$$

where $S$ is the logarithm of new car sales, OIL is the logarithm of the real price of oil (the price of Brent crude measured in national currency and deflated by the GDP deflator), $Y$ is the logarithm of real GDP per capita measured in 2005 USD PPP, POP is the logarithm of population, RIS is the level of the real interest rate (short-term interest rate deflated by the GDP deflator), $\beta_{i}$ is the country fixed effect and $X$ is a set of country-specific variables (such as the unemployment rate, population density, and the old dependency ratio). The subscripts $i$ and $t$ denote country and time. Since for some countries, the gap between actual and predicted sales is very large in 2009 , which might be due to car scrapping schemes and other measures

12. Data on the relative price of cars and on policies that had an impact on car purchases over the estimation period were not available for the panel of countries covered. 
taken by governments in 2009 to support car demand, a dummy variable (taking the value of unity in 2009) are also included in the specification. ${ }^{13}$

20. Equation (1) is estimated on annual panel data with a standard fixed-effects estimator. The panel is unbalanced, with the time span covered for most countries being 2000-2010. A maximum of two lags is included in the short-run dynamics. Insignificant short-run terms are deleted in a stepwise procedure, starting with the least significant term and continuing until all remaining terms are significant at the $10 \%$ level. Data on real GDP, population, exchange rates, the GDP deflator, and the unemployment rate are taken from the World Development Indicators Database of the World Bank. The price of crude Brent is taken from the spring-2013 edition of the OECD Economic Outlook. Data on short term interest rate are taken from the spring-2013 edition of the OECD Economic Outlook for OECD countries and from the World Development Indicators Database of the World Bank for the non-OECD countries.

\subsection{Estimation results}

21. Table 1 provides an overview of the short- and long-run elasticities of car sales with respect to the relevant variables included in the specification. Overall, the estimates are consistent with studies that point to a positive impact of GDP per capita (Eskeland and Feyzioglu, 1997; Mehlin et al., 2004) and a negative impact of oil prices on car ownership (Goodwin et al., 2004; Ryan, 2008).

- The estimates point to a non-linear relationship between car demand and GDP per capita: car sales rise in income, but at a declining rate (Table 1). At the average GDP per capita level of the OECD, the income elasticity of car sales is close to unity which is consistent with previous OECD findings (Haugh et al., 2010). The elasticity is much higher at the average BRIICS income level, equalling 1.6 (Figure 13). These results are robust to changes in the specification (Table 1).

13. The dummy variable is included for countries where the difference between actual and predicted car sales in 2009 was above 15\% and larger than the average residual (in absolute value) over the sample period. These are Austria, Brazil, Estonia, Germany, France, Italy, Japan, Korea, Luxembourg, Slovenia and Turkey. This dummy aims at capturing the effects of car scrapping schemes that had a significant impact on car sales. The dummy variable marginally changes the coefficient value of the other variables and considerably improves the fit of the equation (specifications 1 and 2 in Table 1). Including a dummy for all countries that have introduced subsidies for car purchases during the crisis does not change significantly the results. 
Figure 13. Estimated income elasticity decreases with the level of GDP per capita

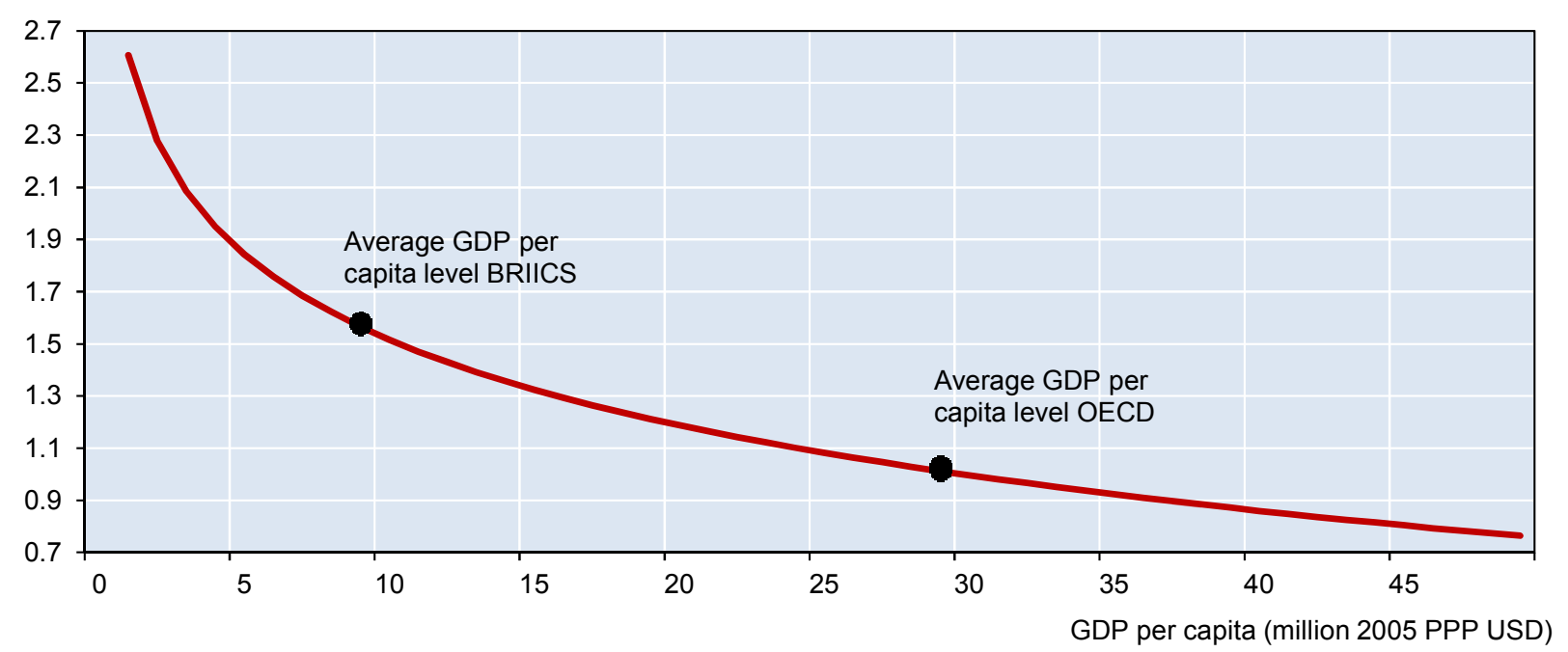

Source: Authors' calculations.

- Unemployment has a negative impact on car sales growth, suggesting that consumers tend to delay the purchase of a car when the risk of losing their job is high. A one percentage point increase in the unemployment rate induces a $0.02 \%$ decline in car sales in the short run which progressively vanishes with time. The sensitivity of car demand to the cycle is also reflected in a strong short-run impact of GDP per capita growth.

- Car sales are found to grow faster than the size of the population. A $1 \%$ increase in population is found to be associated with a $2.4 \%$ increase in car sales. This strong elasticity is difficult to interpret and its statistical significance is quite sensitive to changes in the specification (Table 1). This result may be due to the fact that population increases more in low and middle income countries where car ownership is low but rising. At the same time, this effect should be theoretically caught by the income elasticity.

- Car sales are negatively linked to the real price of oil. A $1 \%$ increase in the real price of Brent crude is associated with a $0.2 \%$ decline in car sales in the long run. The short-run impact of oil price changes is estimated at $-0.15 \%$. The long-run relationship between car sales and real oil prices is not significant when time fixed effects are included (i.e. when the effects of unobserved variables that change over time but not across countries are taken into account, specification 3 in Table 1). This could be an indication that despite differences in exchange rate and inflation developments, real oil prices tend to evolve similarly across countries.

- Estimates do not show a significant impact of real interest rates on car sales, neither in the short nor in the long run (specification 5 in Table 1). As a result, the specification retained for the scenario analysis presented in the paper (specification 1 in Table 1) does not include financial variables and hence does not take into account credit conditions. 
Table 1. Detailed estimation results

\begin{tabular}{|c|c|c|c|c|c|}
\hline & 1 & 2 & 3 & 4 & 5 \\
\hline \multicolumn{6}{|l|}{ Long-run elasticities } \\
\hline GDP per capita $(-1)$ & $\begin{array}{c}5.88^{* * *} \\
(0.00)\end{array}$ & $\begin{array}{c}5.16^{* * *} \\
(0.00)\end{array}$ & $\begin{array}{c}4.92^{* * *} \\
(0.00)\end{array}$ & $\begin{array}{l}1.62^{* * *} \\
(0.00)\end{array}$ & $\begin{array}{c}5.53^{* * *} \\
(0.00)\end{array}$ \\
\hline GDP per capita squared $(-1)$ & $\begin{array}{c}-0.24^{* * *} \\
(0.00)\end{array}$ & $\begin{array}{c}-0.20^{* *} \\
(0.05)\end{array}$ & $\begin{array}{l}-0.18^{*} \\
(0.10)\end{array}$ & - & $\begin{array}{c}-0.24^{* *} \\
(0.02)\end{array}$ \\
\hline Population (-1) & $\begin{array}{l}2.39^{*} \\
(0.10)\end{array}$ & $\begin{array}{l}2.56^{*} \\
(0.06)\end{array}$ & $\begin{array}{l}2.32^{\star *} \\
(0.04)\end{array}$ & $\begin{array}{l}2.33^{*} \\
(0.10)\end{array}$ & $\begin{array}{l}2.57^{\star *} \\
(0.06)\end{array}$ \\
\hline Real oil price $(-1)$ & $\begin{array}{c}-0.22^{\star *} \\
(0.04)\end{array}$ & $\begin{array}{c}-0.21^{* *} \\
(0.04)\end{array}$ & $\begin{array}{l}-0.14 \\
(0.53)\end{array}$ & $\begin{array}{c}-0.26^{\star *} \\
(0.02)\end{array}$ & $\begin{array}{l}-0.15 \\
(0.13)\end{array}$ \\
\hline Real interest rate $(-1)$ & $\begin{array}{l}- \\
-\end{array}$ & $\begin{array}{l}- \\
-\end{array}$ & $\begin{array}{l}- \\
-\end{array}$ & $\begin{array}{l}- \\
-\end{array}$ & $\begin{array}{l}-0.24 \\
(0.18)\end{array}$ \\
\hline \multicolumn{6}{|l|}{ Error correction coefficient } \\
\hline & $\begin{array}{c}-0.33^{* * *} \\
(0.00)\end{array}$ & $\begin{array}{c}-0.34^{* * *} \\
(0.00)\end{array}$ & $\begin{array}{c}-0.38^{* \star *} \\
(0.00)\end{array}$ & $\begin{array}{c}-0.33^{\star * *} \\
(0.00)\end{array}$ & $\begin{array}{c}-0.34^{\star * \star} \\
(0.00)\end{array}$ \\
\hline \multicolumn{6}{|l|}{ Short-run coefficients } \\
\hline$\Delta$ Sales $(-2)$ & $\begin{array}{c}-0.09^{\star *} \\
(0.02)\end{array}$ & $\begin{array}{c}-0.08^{\star *} \\
(0.02)\end{array}$ & $\begin{array}{c}-0.07^{\star *} \\
(0.03)\end{array}$ & $\begin{array}{c}-0.08^{* * *} \\
(0.02)\end{array}$ & $\begin{array}{c}-0.08^{\star \star *} \\
(0.01)\end{array}$ \\
\hline$\Delta$ GDP per capita & $\begin{array}{c}5.07^{\star \star *} \\
(0.00)\end{array}$ & $\begin{array}{c}4.81^{* * *} \\
(0.00)\end{array}$ & $\begin{array}{c}5.00^{* * *} \\
(0.00)\end{array}$ & $\begin{array}{c}4.84^{* * *} \\
(0.00)\end{array}$ & $\begin{array}{c}4.51^{* * *} \\
(0.00)\end{array}$ \\
\hline$\Delta$ Population & $\begin{array}{l}6.63^{* *} \\
(0.04)\end{array}$ & $\begin{array}{l}6.16^{* *} \\
(0.04)\end{array}$ & $\begin{array}{l}7.01^{* *} \\
(0.02)\end{array}$ & - & $\begin{array}{l}5.90^{* *} \\
(0.02)\end{array}$ \\
\hline$\Delta$ Real oil price & $\begin{array}{l}-0.09^{*} \\
(0.05)\end{array}$ & $\begin{array}{c}-0.12^{* * *} \\
(0.01)\end{array}$ & $\begin{array}{c}-0.27^{* * *} \\
(0.00)\end{array}$ & $\begin{array}{c}-0.13^{* * *} \\
(0.00)\end{array}$ & $\begin{array}{l}-0.10^{\star *} \\
(0.04)\end{array}$ \\
\hline$\Delta$ Real oil price $(-1)$ & $\begin{array}{c}-0.08^{* * *} \\
(0.01)\end{array}$ & $\begin{array}{c}-0.07^{* *} \\
(0.01)\end{array}$ & $\begin{array}{c}-0.25^{\star * *} \\
(0.00)\end{array}$ & $\begin{array}{c}-0.07^{* *} \\
(0.01)\end{array}$ & $\begin{array}{c}-0.06^{* *} \\
(0.02)\end{array}$ \\
\hline Unemployment rate & $\begin{array}{c}-0.02^{* * *} \\
(0.00)\end{array}$ & $\begin{array}{c}-0.02^{* * *} \\
(0.00)\end{array}$ & $\begin{array}{l}-0.01^{* *} \\
(0.01)\end{array}$ & $\begin{array}{c}-0.02^{* \star *} \\
(0.00)\end{array}$ & $\begin{array}{c}-0.02^{* * *} \\
(0.00)\end{array}$ \\
\hline \multicolumn{6}{|l|}{ Implied short-run elasticities } \\
\hline GDP per capita & 4.67 & 4.44 & 4.68 & 4.84 & 4.51 \\
\hline Population & 6.11 & 5.69 & 7.18 & - & 5.90 \\
\hline Real oil price & -0.15 & -0.18 & -0.47 & -0.18 & -0.09 \\
\hline Sample (adjusted) & $1999-2010$ & $1999-2010$ & $1999-2010$ & $1999-2010$ & $1999-2010$ \\
\hline Countries included & 56 & 56 & 56 & 56 & 55 \\
\hline Dummy 2009 & yes & no & no & no & no \\
\hline Country fixed effects & yes & yes & yes & yes & yes \\
\hline Time fixed effects & no & no & yes & no & no \\
\hline Total panel (unbalanced) observations & 584 & 584 & 584 & 584 & 565 \\
\hline
\end{tabular}

Note: All variables except the real interest rate and the unemployment rate are measured in logarithms. Asterisks $\left({ }^{*},{ }^{* *},{ }^{* * *}\right)$ indicate the significance level $(10 \%, 5 \%, 1 \%)$ of the coefficients. P-values are in parenthesis. - indicates that the variable is not included in the specification.

\section{Capacity expansion will be required, but mostly in emerging countries}

22. Using the estimated relationship discussed in section 4 (specification 1), a scenario analysis is conducted to assess the short- and medium-term prospects of the car industry. A baseline scenario showing the profile of sales in each country until 2020 is constructed based on the projected values of the main determinants (specification 1, Table 1). The GDP, population, and inflation growth rates are taken from the projections of the spring-2013 OECD Economic Outlook for OECD and BRIICS countries. For the other 
countries assumptions are made based on OECD or BRIICS countries in the same geographic area. ${ }^{14}$ Overall, this implies that GDP per capita will grow at around $2 \%$ per year in OECD countries and at around 4\% per year in non-OECD countries over the period 2013-20. Unemployment projections also follow the spring-2013 OECD Economic Outlook for OECD countries, with structural unemployment in OECD countries assumed to gradually return to the lowest value estimated between 2007 and 2013. For non-OECD countries unemployment is assumed to evolve in line with other countries in the same geographic area (if available) or otherwise in line with the OECD average. The nominal price of oil is assumed to increase by $5 \%$ per year in USD terms. ${ }^{15}$

\subsection{Car sales growth is set to increase only marginally in the OECD over the next two years}

23. The estimated relationship used to compute the projections allows assessing the level of pent-up demand by indicating where current sales stand relative to what fundamentals would suggest and projecting car sales over the coming years. The results, which are based on specification 1 in Table 1, suggest that in the majority of countries car sales were well below the value implied by economic fundamentals in 2012 (Figure 14). The corresponding tendency for car sales to bounce back may not materialise over the next two years, however, as short-term developments also depend on the evolution of short-term conditions:

- In several European countries sales are projected to continue their decline in 2013-14. While in France and Spain the estimated drop in car demand reflects low growth prospects and higher unemployment, in the United Kingdom, it reflects in part higher oil import prices due to the recent depreciation of the British Pound.

- In Germany, car sales are projected to stabilise over the next two years, with demand adjusting to fundamentals. In Italy, sales are estimated to rise somewhat, reflecting both improving economic prospects and the weak starting point, with car sales currently well below what corresponds to estimated long-term equilibrium.

- Car sales are estimated to decline in Japan after a sharp increase in 2012 backed by government tax incentives and purchasing subsidy programmes for fuel-efficient vehicles. Increases in oil prices driven by the recent depreciation of the yen also play a role in this drop.

- Even though a steady recovery in incomes in North America since 2010 has boosted car sales, demand has remained below levels consistent with current average income levels and oil prices. As a result, further increases in sales are projected over the next two years, but possibly at a slower pace compared with the past two years.

- In the BRICS a continued strong increase in car sales is to be expected over the next two years, reflecting strong GDP per capita growth.

14. For countries not covered by the Economic Outlook, growth rates of GDP per capita, population, and inflation are computed as the simple average of the growth rates of these variables in countries located in the same region and for which data are available. Exchange rates are projected to increase at the same rate as over the past five years.

15. In the projections, growth rates of real oil prices expressed in national currency units vary across countries following country-specific movements in real exchange rates. 
Figure 14. Car sales are below their trend level in most countries Actual and underlying car sales, in millions of units
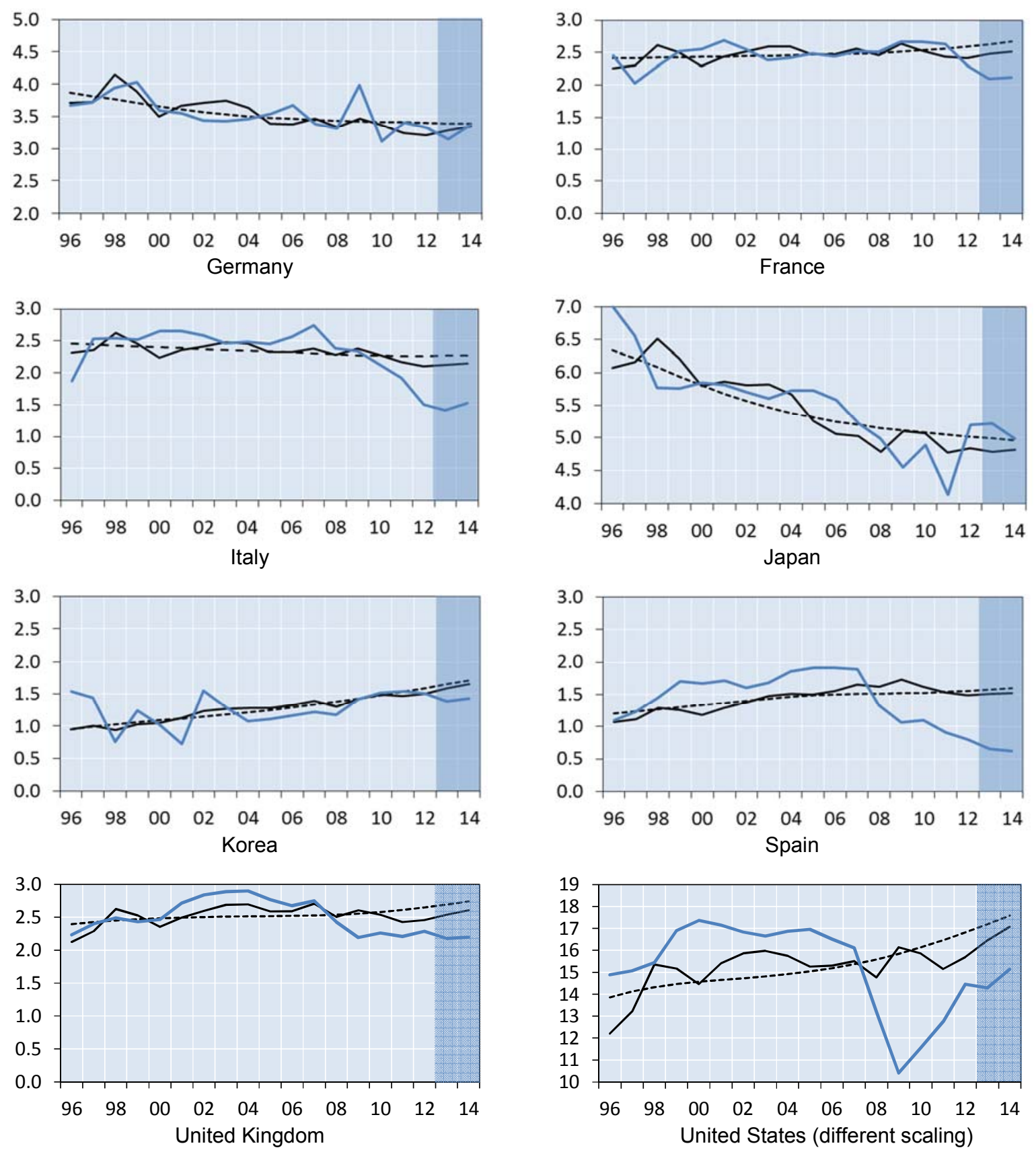

- Actual sales

- Underlying sales based on actual values of explanatory variables

-.--.- Underlying sales based on trend values of explanatory variables

Note: The figures compare actual sales to underlying sales, which are computed based on the long-term part of equation (1). Underlying sales are alternatively computed based on actual and trend values of the explanatory variables. To illustrate interpretation, take the case of the United States in 2012. Actual sales were 10\% below what would be suggested by the actual level of the real price of oil, income per capita and the size of the population in that year. However, these explanatory variables were themselves not in equilibrium in that year; in particular, the economy suffered from a sizeable negative output gap as a consequence of the crisis. Accounting for this and evaluating all explanatory variables at their trend values suggests that sales were $16 \%$ below the level that would have prevailed had the economy been in equilibrium in 2012.

Source: Authors' calculations. 
24. To assess the implications of these projections for car demand on capacity utilisation of car assembly plants, trade flows need to be taken into account. ${ }^{16}$ Although cars are rarely traded between the major regions, intra-regional trade is sizeable. Hence, domestic sales do not provide a very meaningful picture of individual countries' production prospects. For each country, car imports are derived from the import penetration rates observed in the automobile industry in 2011 and the projections of car demand. ${ }^{17}$ Exports are computed based on the estimated imports and countries export market shares in $2011 .{ }^{18}$ Both import penetration rates and export market shares are assumed to remain constant over the projection period.

25. The analysis indicates that overall the changes in the demand for cars projected over the next two years are unlikely to significantly reduce the excess capacity observed in many OECD countries. Car plants in Europe will most likely benefit only to a limited extent from additional demand in emerging countries because trade flows, as mentioned earlier, are largely concentrated within large regional markets and car demand within Europe is set to remain weak in the near term. In France and Spain, capacity utilisation might thus even decline further on the back of weakening domestic demand (Figure 15). In Italy, capacity utilisation will not improve as growth in domestic car sales is set to be mostly absorbed by foreign competitors and demand in Italy's export markets remains subdued. ${ }^{19}$ More generally, the projected rise in car sales on average in OECD countries until 2014 is relatively minor compared to the overall level of overcapacity.

Figure 15. Capacity utilisation is unlikely to improve in Western Europe

Projected change in capacity utilisation rate, in percentage points, 2012-2014

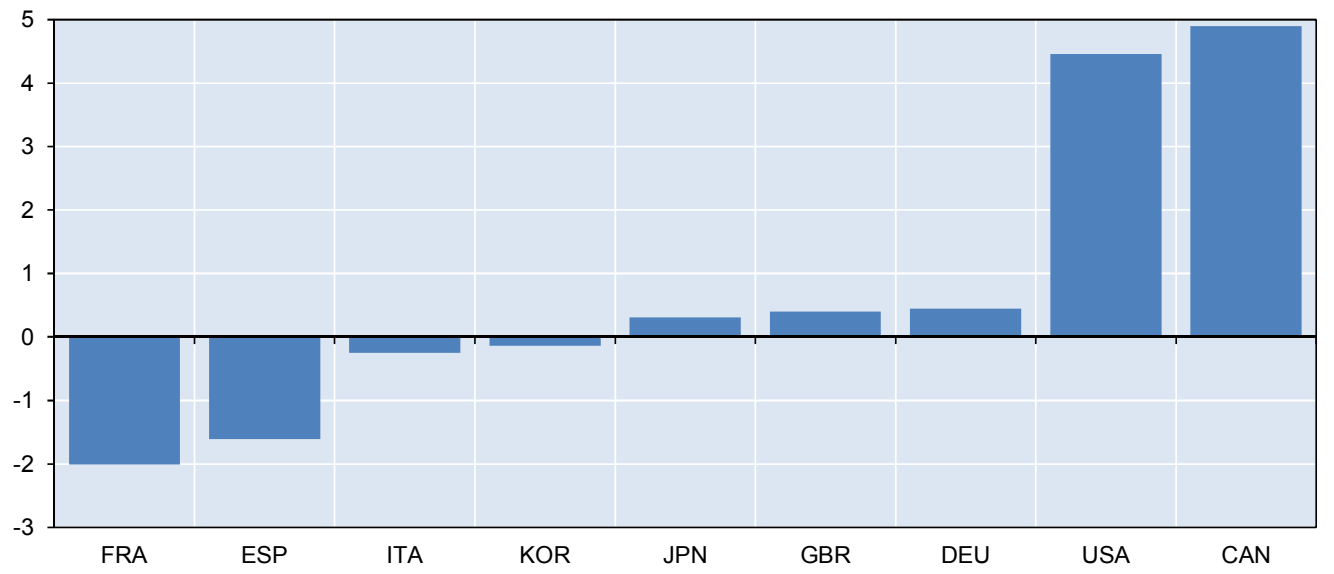

Note: The chart shows the difference between the capacity utilisation rate in 2014 and in 2012, assuming that only production changes between the two years whereas capacity in 2014 is the same as in 2012.

Source: Authors' calculations and LMC Automotive database.

16. The role of inventories is ignored in the analysis due to the lack of adequate data.

17. Data on trade flows are taken from UNComtrade. The computation of market shares and import penetration ratios is based on 2011 trade data because this is the last year for which data are available for a representative share of world trade. Since the trade data do not exactly match the car sales and production data for 2012, export market shares for 2012 are computed by adjusting 2011 trade flows such that domestic car sales, adjusted for 2011 import penetration ratios, plus exports equal production for all countries in the sample.

18. $E_{i}$ car exports of country $i$ are given by $E i=\sum_{j} M_{j} \times S_{i j}$, with $M_{j}$ the imports of cars of country $j, S_{i j}$ the export market share of $i$ in $j$.

19. Italy is a net importer of cars. 
26. The decline in capacity utilisation in recent years is due to cyclical factors, but certainly also relates to more fundamental drivers, in particular to abovementioned structural changes in demand patterns. To assess how much of the current overcapacity is due to the crisis and how much is structural in nature, capacity utilisation rates are computed for 2012, assuming that all explanatory variables in equation (1) were equal to their trend values and that car sales were in line with those fundamentals (i.e. demand in all countries is assumed to have been equal to the dotted lines in Figure 14). The analysis indicates that the crisis can explain a sizeable part of the overcapacities in Spain and Italy (Figure 16). Still, in Italy capacity utilisation would have been well below $80 \%$ had all economies been in equilibrium in 2012. The same applies to France, where the crisis appears to have contributed only 7 percentage points to the overcapacity problem. Among the nine countries shown in Figure 16, Canada is the only one where capacity utilisation would have been lower if sales in all countries had been equal to trend.

Figure 16. The cyclical situation does not fully explain overcapacity in some countries

In \% of total production capacity

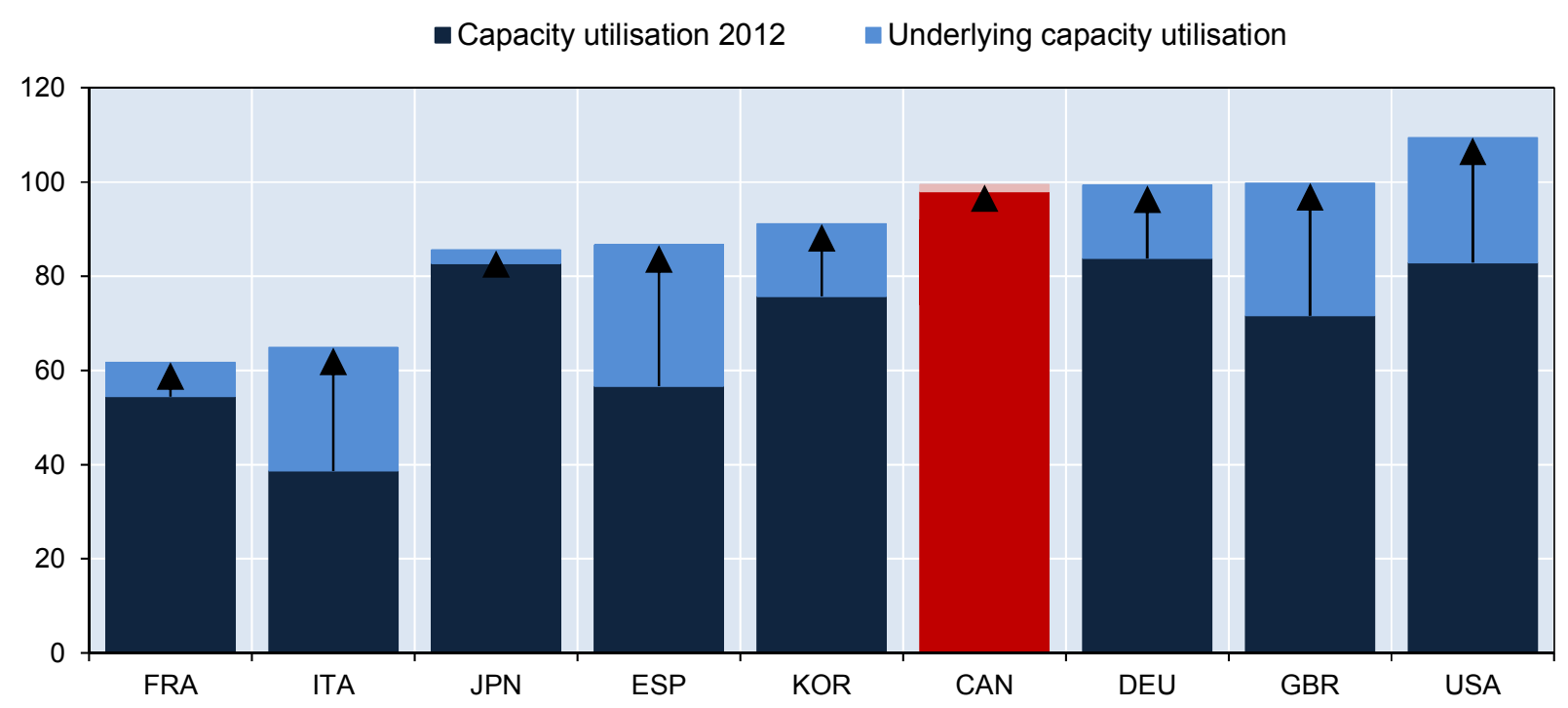

Note: "Structural capacity utilisation rates" are capacity utilisation rates in 2012 if car sales in all countries had been equal to trend. Source: Authors' calculations and LMC Automotive database.

27. These model-based projections are surrounded by considerable uncertainty. In particular, they are based on a simple estimated relationship, which ignores a range of potentially relevant factors that influence the demand for passenger cars in the short term. For example, strong competition in the car market relating to current overcapacities might continue to weigh on the relative price of cars, thereby supporting car purchases. Besides, the observed increase in the average age of cars is not taken into account in the model. The ageing of the car fleet might be structural - on the back of increased quality of cars for instance - and continue further in the future. This may induce a change in the link between car sales and the factors included in the analysis. Moreover, even though this could not be captured in the context of the simple empirical relationship presented above, financial conditions might play a role in some countries. ${ }^{20}$ Improvements in the access to credit and falling costs might contribute to a rise in demand by making cars more affordable. Finally, the structural level of capacity utilisation is uncertain as it depends

20. Interest rates might be too crude as a measure of financial conditions to adequately capture the access to credit for car purchases. 
to a large extent on how the trend values of the explanatory variables are measured. ${ }^{21}$ In particular, the results are sensitive to changes in trend GDP estimates, with an overestimation of potential growth lowering the structural share of the observed overcapacity issues.

\subsection{Over the medium run demand is expected to grow mainly in Asia and South America}

28. The medium-run projections - taken at face value - suggest that strong GDP per capita growth in emerging markets in Asia and South America would trigger a rapid increase in passenger car sales over the next few years in these regions (Figure 17). At the global level, the number of car sales is set to increase by 5.7 million units per year on average, with $75 \%$ of this increase coming from non-OECD countries (Table 1). This is somewhat higher than the increase projected, for instance, by LMC Automotive which puts the increase at a bit more than 4 million per year.

Table 2. Main results of the medium-term projections

Baseline scenario

\begin{tabular}{lccccccc}
\hline & OECD & $\begin{array}{c}\text { non- } \\
\text { OECD }\end{array}$ & Asia & $\begin{array}{c}\text { North } \\
\text { America }\end{array}$ & $\begin{array}{c}\text { South } \\
\text { America }\end{array}$ & Europe & World \\
\hline $\begin{array}{l}\text { Total sales in 2012 } \\
\text { (million units) }\end{array}$ & 46.2 & 35.1 & 40.0 & 15.3 & 4.2 & 16.9 & 81.3 \\
$\begin{array}{l}\text { Total sales in 2020 } \\
\text { (million units) }\end{array}$ & 57.6 & 69.5 & 71.8 & 19.4 & 5.6 & 21.8 & 127.1 \\
$\begin{array}{l}\text { Average growth rate of total } \\
\text { sales rate (in \%) }\end{array}$ & $3 \%$ & $9 \%$ & $8 \%$ & $3 \%$ & $4 \%$ & $3 \%$ & $6 \%$ \\
$\begin{array}{l}\text { Contribution to world sales } \\
\text { growth (in \%) }\end{array}$ & $25 \%$ & $75 \%$ & $69 \%$ & $9 \%$ & $3 \%$ & $11 \%$ & $100 \%$ \\
$\begin{array}{l}\text { Capacity in 2012 } \\
\text { (million units) }\end{array}$ & 60.1 & 52.8 & 56.9 & 17.4 & 5.7 & 25.7 & 112.9 \\
$\begin{array}{l}\text { Capacity needed in 2020 } \\
\text { (million units) }\end{array}$ & 67.8 & 81.8 & 84.5 & 22.8 & 6.6 & 25.6 & 149.6 \\
$\begin{array}{l}\text { Required capacity increase } \\
\text { (in million units) }\end{array}$ & 7.7 & 29.0 & 27.6 & 5.4 & 0.9 & -0.1 & 36.6 \\
$\begin{array}{l}\text { Required capacity increase } \\
\text { (in \% of 2012 capacity) }\end{array}$ & $13 \%$ & $55 \%$ & $48 \%$ & $31 \%$ & $16 \%$ & $0 \%$ & $32 \%$ \\
\hline
\end{tabular}

Note: Capacity needed in 2020 corresponds to the capacity needed to maintain a capacity utilisation rate of $85 \%$ in 2020 . The $85 \%$ utilisation rate was chosen because it is close to the utilisation rate observed in OECD countries on average over the past two decades in the manufacturing sector (around $80 \%$ ) and to the optimal utilisation rate as suggested by the experts of the automobile industry (between $80 \%$ and $90 \%$ ). The results do not change significantly when the capacity utilisation rate is set at $80 \%$ or $90 \%$.

Source: LMC Automotive, authors' calculations.

21. The trend level of the explanatory variables significantly depends on the methodology used for its estimation (Bagnoli et al., 2013). 
29. At the regional level, the following conclusions emerge:

- In Asia, sales growth would be mainly driven by China, which would account for $40 \%$ of total growth (India would account for another 14\%). This result is in line with findings of Chamon et al. (2010), who project a 10\% annual increase in the stock of cars in China between 2010 and $2020 .^{22}$

- In Korea, sales would be growing by $2 \frac{1}{2}$ per cent per year over the projection period and in Japan they would slightly fall on account of a shrinking population.

- Growth is projected to be rather sluggish in North American and European OECD countries, at a rate of 3\% per year. The figure for Europe hides important differences across countries, due not least to different cyclical conditions. While car sales in Austria, Denmark and Germany are projected to fall slightly, Italy and Spain would experience growth of 5\% and Portugal of $71 / 2$ per cent as a consequent of a rebound in GDP per capita growth. In Greece, car sales, which are currently very depressed, might even go up by as much as $13 \%$ per year.

Figure 17. Passenger car sales will grow rapidly in Asia and South America

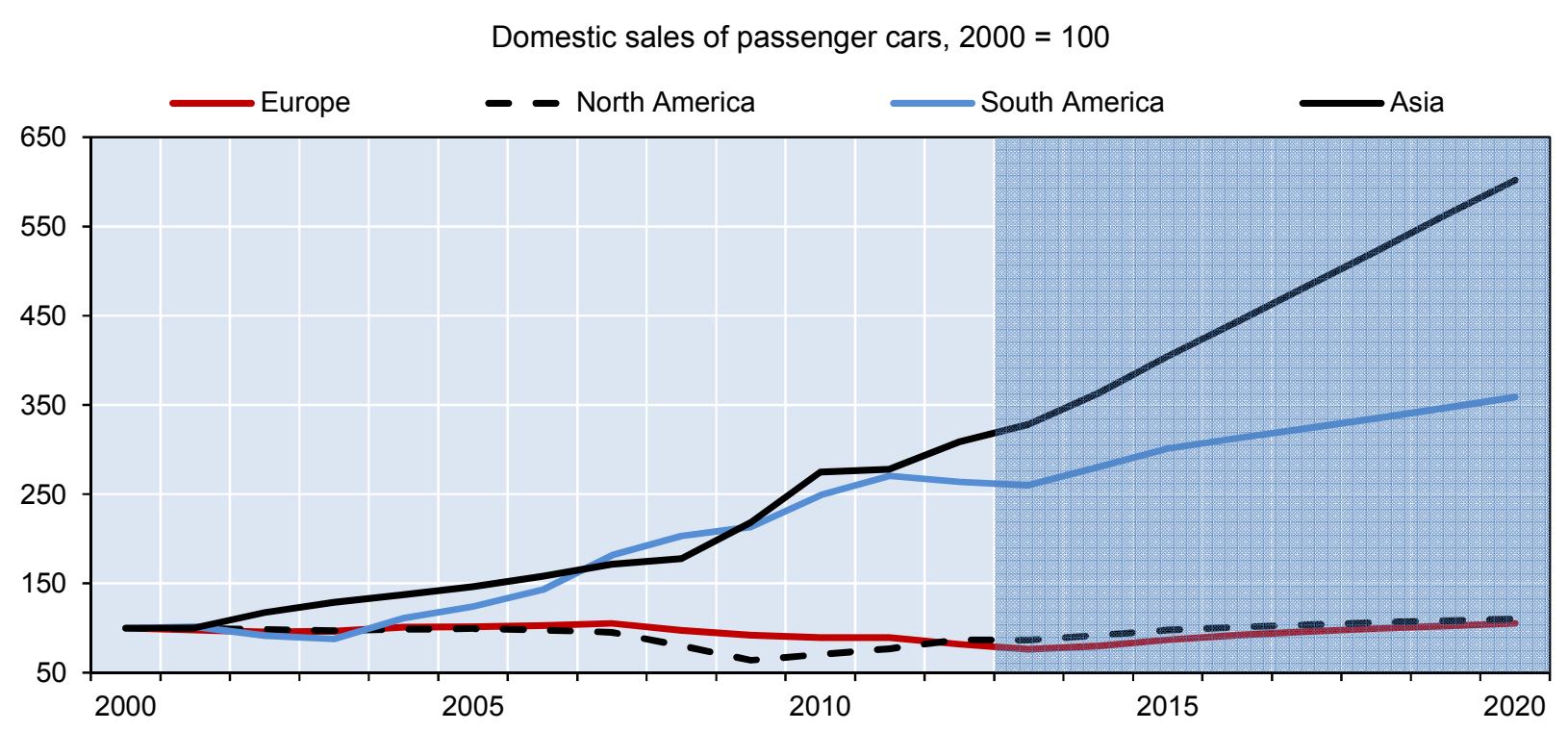

Source: Authors' calculations.

30. To account for international trade in passenger cars, domestic sales are adjusted for net exports as detailed above. Assuming that export market shares and import penetration remain constant from their 2011-2012 levels, the analysis shows that the outlook for production in Japan, Germany and the United Kingdom might be better than that for domestic sales as these countries are net exporters of passenger cars to markets that grow faster than their domestic markets (Figure 18). The reverse is true for Mexico, Turkey and Italy, among others.

22. Assuming a constant scrapping rate of $6 \%$ (as in Haugh et al., 2010), the baseline projections imply a stock of cars close to the one estimated by Chamon et al. (2010) for China in 2020. 
Figure 18. Production prospects depend on both domestic sales and international trade patterns

Annual growth in passenger car demand in selected countries in per cent, 2013-2020

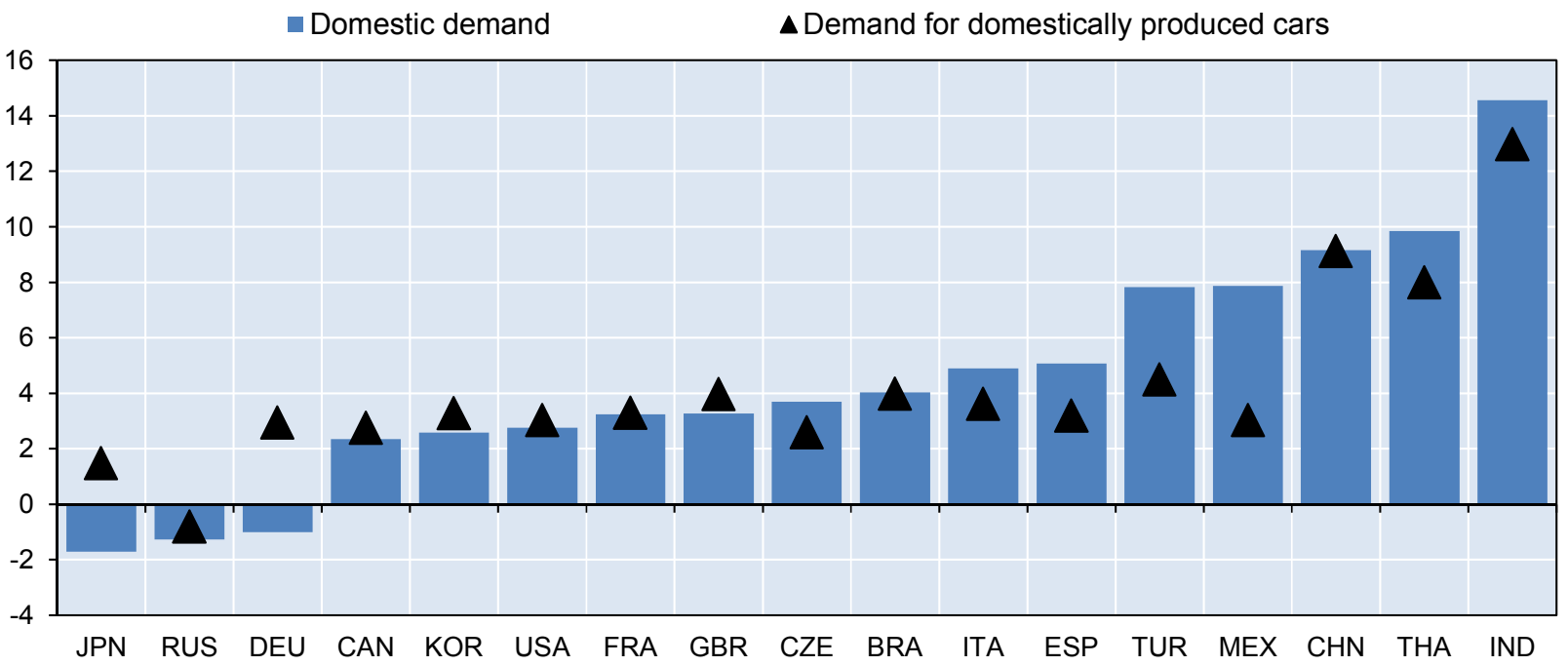

Source: Authors' calculations.

\subsection{Only a few European countries might have overcapacities in the medium run}

31. To gauge the implications of these projections for the need to expand or downsize production capacity, projected production levels in 2020 in individual countries and regions are compared with actual capacity in 2012. Overall, the projections indicate that additional production capacity of around 35 to 40 million cars would be required to meet global car demand over the next eight years, with quite huge differences across regions (Table 1). In Europe, excess capacity might be absorbed by 2020 and the need for additional capacity is likely to be limited. By contrast, in Asia, North America and South America, capacity may have to increase by around $50 \%, 30 \%$ and $15 \%$, respectively, to meet future demand. In Asia, capacity expansion will probably mainly materialise in non-OECD countries. As shown in Figure 19, the countries with the biggest projected additional capacity needs are India ( 7 million vehicles or $120 \%$ of 2012 capacity) and China (141/2 million vehicles or 50\% of 2012 capacity).

32. Car manufacturers are already heavily investing in new capacity in China by opening car assembly plants (e.g. PSA in Wuhan, Ford in Nanchang). The planned capacity targets announced by automakers suggest that manufacturing capacity would increase from 28.5 million in 2013 to 40 million vehicles by the end of 2015 (KPMG, 2012). LMC Automotive also expects capacity in China to reach around 40.5 million units by 2020 . With this amount of capacity, an utilisation rate of $90 \%$ would be required to meet the demand implied by the baseline projections for 2020 . To bring utilisation down to $85 \%$, additional capacity of around 2 million units would be needed. 
Figure 19. Some European countries might need to reduce capacities

Capacity surplus and deficit in major car producing countries by 2020 , in millions units

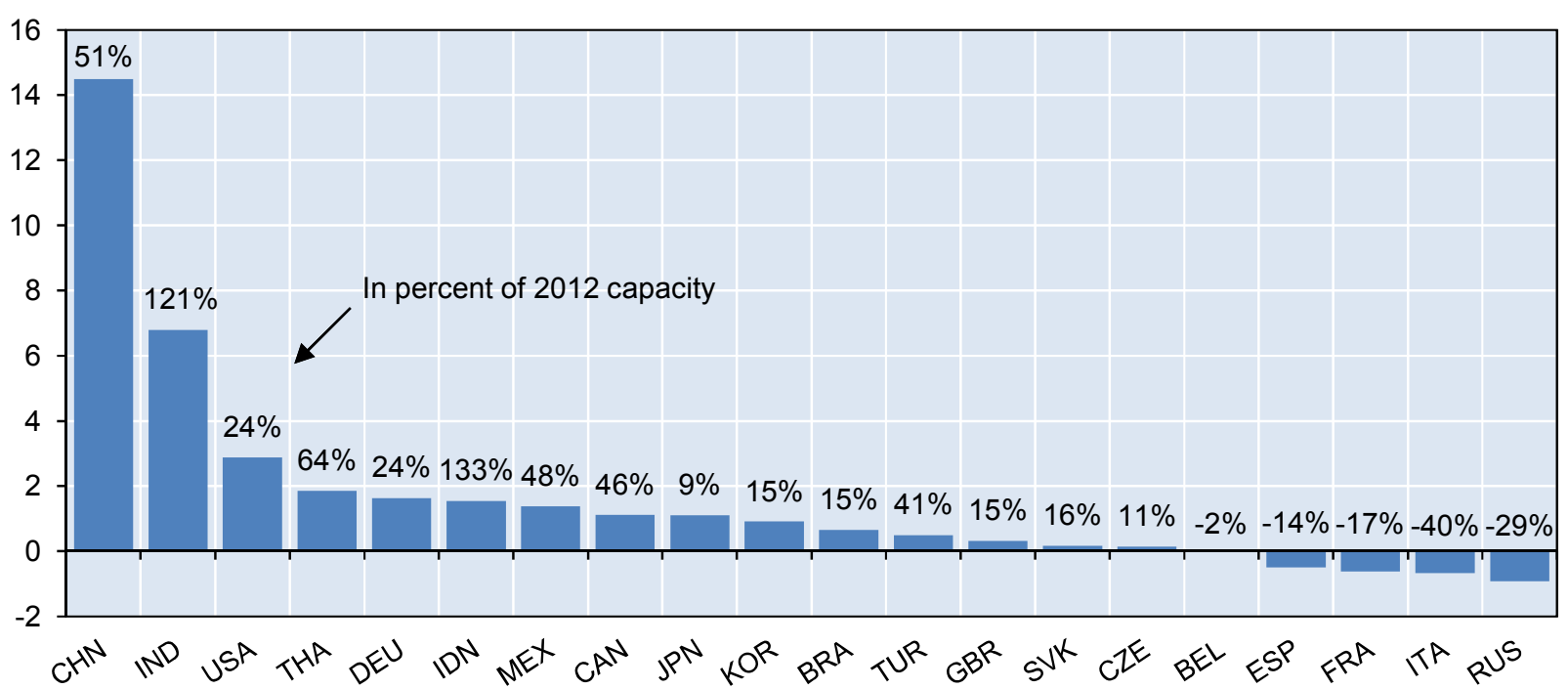

Note: The bars show the required capacity adjustment assuming a capacity utilisation rate of $85 \%$ in 2020 . The choice of the $85 \%$ utilisation rate was motivated by the average utilisation rate observed in OECD countries in the manufacturing sector (around $80 \%$ ) and the desired utilisation rate as suggested by experts of the automobile industry (between $80 \%$ and $90 \%$ ). The results do not change significantly when the capacity utilisation rate is set at $80 \%$ or $90 \%$.

Source: Authors' calculations and LMC automotive database.

33. In Europe as a whole, excess capacities are projected to be progressively absorbed by 2020 . However, there are important differences across countries, with sizeable overcapacity in Italy, Spain, and France, but capacity shortfalls in Germany and several Eastern European countries. This is in line with the idea that while car producers could use idle capacities to meet demand on the European market, they may prefer expanding capacities in countries with a comparative advantage and cutting capacities in less attractive locations, as they did in the past. Some countries, including Slovakia, Spain, Germany and the Czech Republic appear in a good position to gain from an eventual rebound in demand in Europe as they have relatively strong comparative advantages (Figure 20). As such, in absence of changes in the relative competitiveness level of European countries, the shift in production from Western to Eastern Europe might continue in the future. Downsizing has already started in Western Europe, with three plants having been closed since 2007 (the Opel plant in Antwerp, the Fiat plant in Termini, and, at least temporarily, the Saab plant in Trolhattan). Further closures of car assembly plants have been announced for the next few years (in Southampton, Genk, Aulnay, and Bochum).

34. Plant closures will probably contribute to reduce overcapacity but their impact on excess capacity is difficult to assess. Indeed, cutting production capacities may reduce future sales of domestically produced cars. Car demand that was previously met by the closed plants will not necessarily remain in the country because the cars produced by domestic producers may not be a substitute for those previously produced in the closed plants, in particular if the types of models are different or if the terminated production is relocated in another country. For instance, it is very unlikely that the fall in car sales induced by the closure of Genk will be fully compensated by domestic production elsewhere in Belgium. The Genk plant accounts for around $36 \%$ of total productive capacity in Belgium and the current production will be transferred to other plants in Spain. By contrast, the level of sales in Germany might not be significantly affected by the planned downsizing in Bochum because the current production in Bochum will be transferred to another plant in Germany (Rüsselsheim). Assuming that half of the production of the closed 
plants stays in the countries, simple calculations suggest that the capacity utilisation rate might increase by 25 percentage points in Belgium, 2 percentage points in Germany, France and the United Kingdom. ${ }^{23}$

Figure 20. Comparative advantages diverge across European countries

Revealed comparative advantage, 2007 and 2011

- $2011 \quad \Delta 2007$

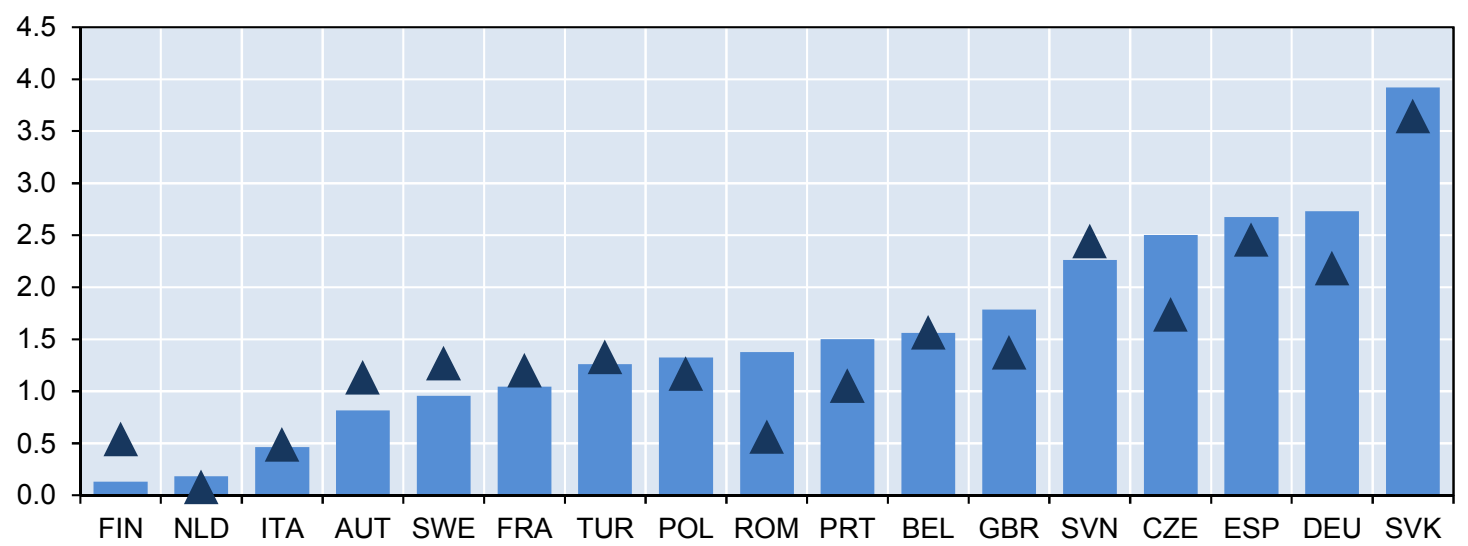

Note: Revealed comparative advantages are measured as the ratio of a country's share of world exports in the automobile sector (7812 in ISIC rev3) to its share of exports overall.

Source: Author's calculations, ComTrade database.

\subsection{The results depend on the assumptions about policies and macroeconomic conditions}

35. As mentioned above, the baseline projections are surrounded by a high degree of uncertainty. Prospects for car sales crucially hinge on assumptions about GDP, population and oil price developments as well as on the responsiveness of car sales to these factors. Moreover, policy action to deal with environmental problems might strongly influence future car demand and are not accounted for in the simple framework used above. To shed further light on these issues, a number of alternative simulations are carried out (Figures 21, 22, and 23).

- If economic growth were lower than assumed in the baseline scenario, demand for cars would increase less strongly, reducing the need for future capacity expansions at the global level. For example, if annual growth in the BRIICS was one percentage point lower than in the baseline scenario, global car demand in 2020 would end up $8 \%$ below the value implied by the baseline scenario (Figure 21). Global car sales are less sensitive to assumptions about GDP per capita growth in advanced countries, reflecting a lower responsiveness of car demand to changes in GDP per capita in these countries. For instance, if GDP in Europe and North America grew annually by one percentage point less than in the baseline, global car demand would be 5\% lower in 2020.

23. Assuming that future car sales remain unchanged compared with the baseline projections (i.e. that the total production of the closed plants stays in the country), the closure of the plants in Aulnay, Southampton, and Bochum is projected to increase the capacity utilisation rate in France, in the United Kingdom, and in Germany by 3 percentage points by 2014. Under the same assumption, the capacity utilisation rate in Belgium is set to increase by around 40 percentage points after the closure of Genk. By contrast, assuming that the production does not stay in the country, the capacity utilisation rate is projected to increase by 12 percentage points in Belgium, 2 percentage points in the United Kingdom, 1 percentage point in Germany and to remain unchanged in France. 
- Since cars are mostly traded within regions, different assumptions on GDP per capita growth in a specific region or country mainly affect car production in countries of that region. For instance, the one percentage point decline in GDP per capita growth in the BRIICS is projected to raise overcapacity by only 300000 cars in Europe (around one per cent of 2012 capacity), but to cut capacity needs by 10 million cars in Asia (18\% of 2012 capacity). Conversely, European countries are set to hardly benefit from higher GDP growth in emerging markets in terms of a boost to car production in Europe (Figure 22).

Figure 21. Prospects for car sales are sensitive to the assumptions underlying the projections Differences in car sales in 2020 compared with the baseline scenario, in \%

$\begin{array}{cccc}\text { Nominal oil price } & \leqslant 1 \text { pp lower GDP } & 1 \mathrm{pp} \mathrm{lower} \mathrm{GDP} \mathrm{per} \\ \text { growth cut in half } & \begin{array}{l}\text { Income elasticity } \\ \text { per capita }\end{array} & \text { cap. growth in OECD } & \text { of China cut to } \\ & \text { growth in BRIICS } & \text { Europe \& NAFTA } & \text { OECD average }\end{array}$

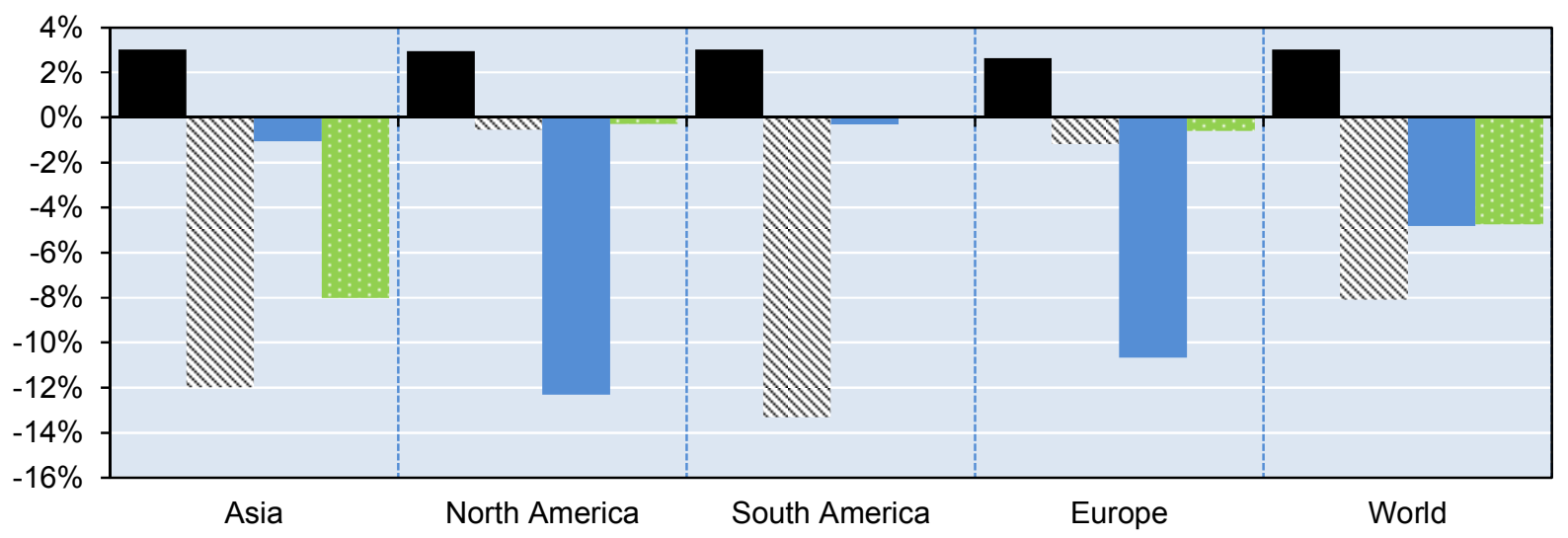

Note: Income elasticity of sales to GDP per capital of China is cut from 1.7 to unity (the OECD average).

Source: Authors' calculations and LMC automotive database.

Figure 22. Capacity required to satisfy future demand is uncertain

Required extra capacity in 2020 in millions units

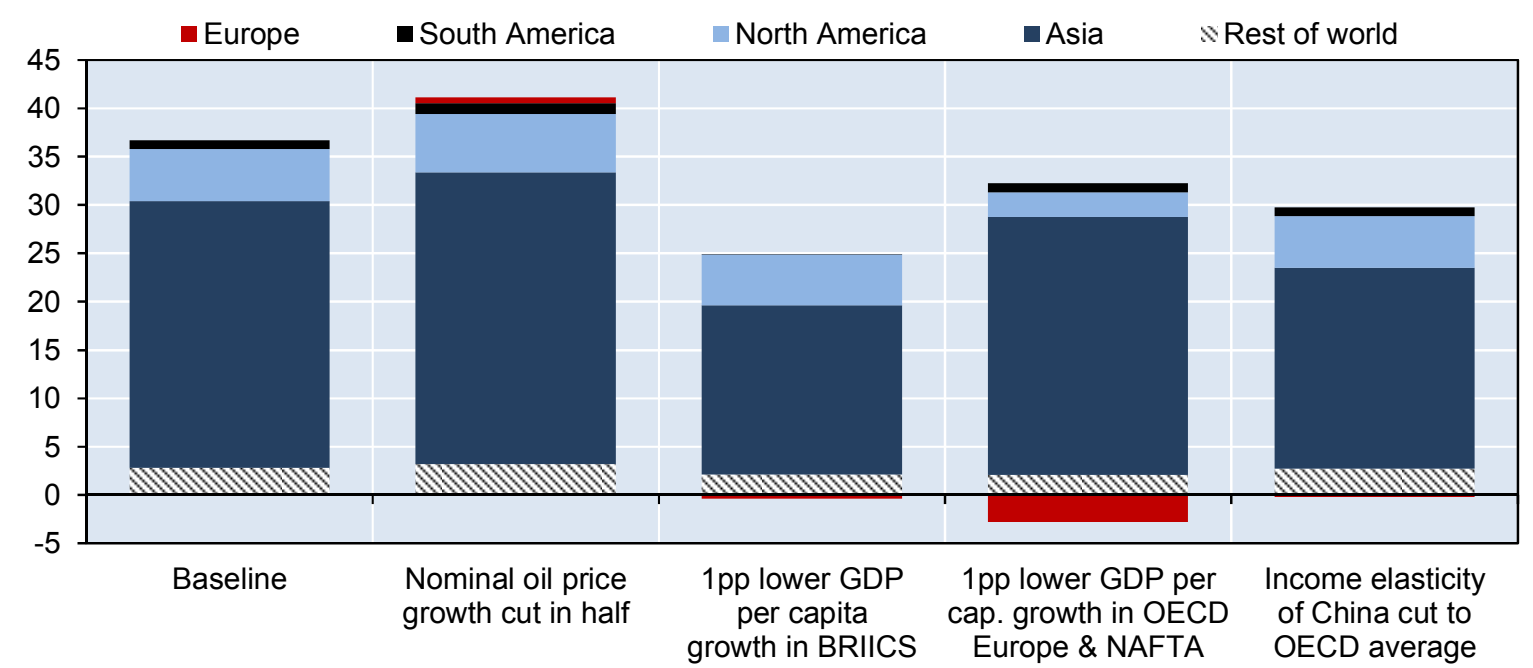

Note: Capacity projections assume a capacity utilisation rate of $85 \%$ in all countries. Income elasticity of sales to GDP per capital of China is cut by $10 \%$, resulting to a decline of total income elasticity from 1.7 to 1.1 .

Source: Authors' calculations and LMC automotive database. 
- To investigate the implications of alternative oil price assumptions on the results, nominal oil price growth is cut in half relative to the baseline, which is broadly equivalent to maintaining the price of oil constant in real terms over the projection period. In nominal terms, the price of Brent crude reaches USD 130 in 2020 (compared with USD 160 in the baseline). In this scenario, car demand at the world level would be $3 \%$ higher than the level projected in the baseline, inducing an increase in extra capacity required to satisfy demand of around 4.5 million units. However, the distribution of car production across countries and regions would hardly change, and thus would not do much to reduce overcapacity in Western Europe.

- Likewise, moderate improvements in competitiveness would barely help to reduce overcapacity in Western Europe. For example, raising the export market shares of Spain, France, and Italy by $10 \%$ would still leave them with sizeable overcapacities (Figure 23) and increase car production in Europe only by $3 \%$ compared with the baseline.$^{24}$ For these three countries to achieve a capacity utilisation rate of $85 \%$, their market shares would need to increase by respectively $20 \%, 30 \%$ and $100 \%$.

- The baseline scenario abstracts from the influence of changes in economic policy on car demand. However, measures taken by governments to ease congestion and reduce greenhouse gas and other emissions may dampen demand by restricting car ownership or raising its cost. The issue may be particularly relevant for emerging markets where car ownership is rising rapidly, with associated congestion and pollution problems. Reducing the responsiveness of car demand to income in China to the OECD average (from 1.7 to 1 ) is the option chosen here to illustrate the potential impact of stricter environmental regulation on car demand. For instance, such a weaker link between GDP per capita and car sales could result from an extension of the lottery schemes that already exist in several Chinese cities to limit the number of new car registrations. The lower responsiveness of car sales in China to changes in income would reduce car sales by $5 \%$ worldwide by 2020 relative to the baseline (Figure 21). This would mainly affect production in China because most of the cars sold in this country are produced domestically.

\section{Figure 23. Overcapacities persist in several EU countries under various scenario assumptions}

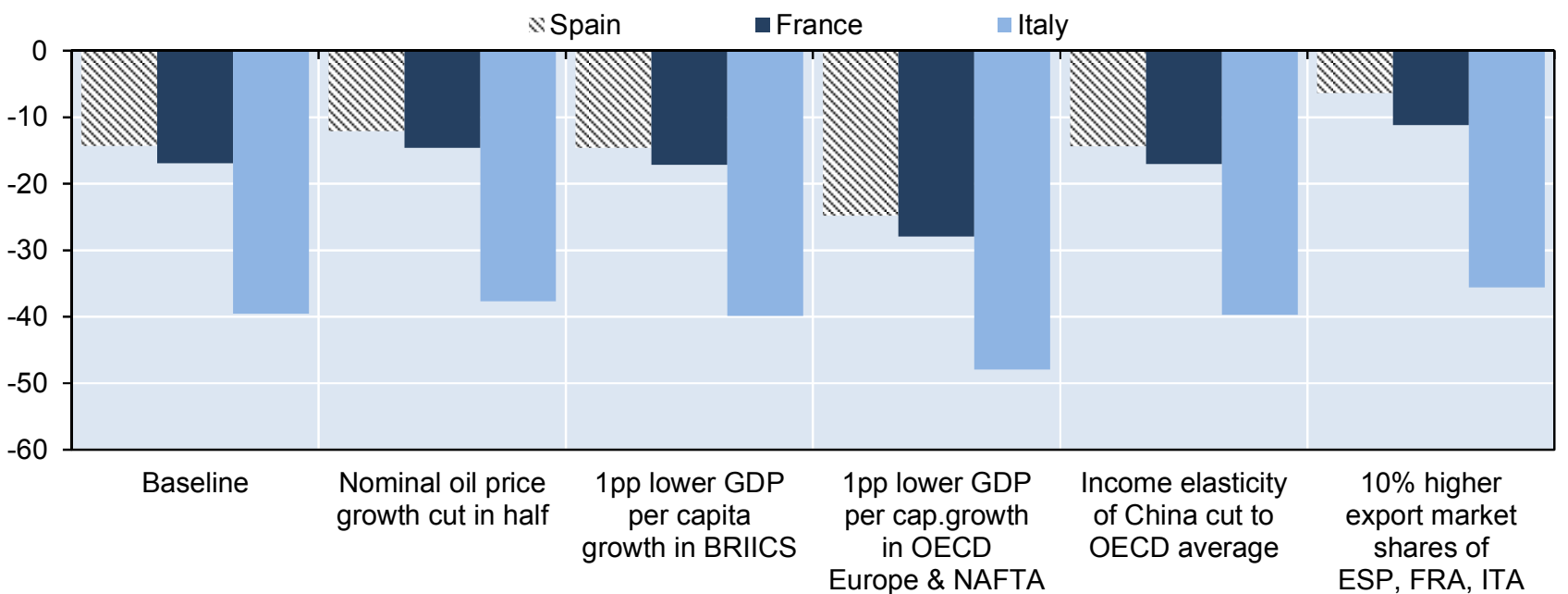

24. The scenario assumes that the increase in these three countries' market shares is offset by a corresponding decline in the market share of the rest-of-the-world group. 
Note: Capacity projections assume a capacity utilisation rate of $85 \%$ in all countries. The income elasticity of sales to GDP per capita of China is cut by $10 \%$, resulting in a decline of the income elasticity from 1.7 to unity (OECD average).

Source: Authors' calculations and LMC automotive database.

36. The fact that the projections do not take into account changes in consumer preferences is another limit to the analysis. For instance, demand for small cars is likely to increase further in the medium term. A simple equation is estimated to assess the relative development of small car sales in a number of OECD and non-OECD countries (Box 1). The share of small cars in total car sales in the OECD is projected to rise by 5 percentage points by 2020. While some car factories are flexible enough to easily shift production from one type of car to another, for others extra investment will be needed to adjust production facilities in a way that would allow them to produce smaller models. Countries' relative capacity to attract investment and to adapt to innovation is not reflected in the projections but will certainly play an important role for the location of car production in the future. Investment will be needed to adapt to the increasing demand for fuel efficient and interconnected cars. Adaptive capacities will be required to incorporate new technologies in the car production, even at the assembly stage.

\section{Box 1. Projections of the share of small cars in total demand}

To assess the extent of the potential shift in demand towards smaller cars over the next years, a simple error correction model is estimated for a panel of 44 OECD and non-OECD countries ${ }^{1}$ that links the share of basic, subcompact, compact cars in total car demand to GDP per capita and the real price of oil. Indicators for the level of urbanisation and the age structure of the population are also added in the specification.

$$
\begin{aligned}
\operatorname{SMALL}_{i, t}= & \propto\left(\operatorname{SMALL}_{i, t-1}-\beta_{\text {oil }} O I L_{i, t-1}\right)+\sum_{j=1}^{2} \gamma_{S}^{j} \Delta S M A L L_{i, t-j}+\sum_{j=1}^{2} \gamma_{O I L}^{j} \Delta O I L_{i, t-j} \\
& +\sum_{j=1}^{2} \gamma_{Y}^{j} \Delta Y_{i, t-j}+\sum_{j=1}^{2} \gamma_{x}^{j} X_{i, t-j}-\beta_{i}
\end{aligned}
$$

where SMALL is the share of basic, subcompact, compact cars in total car demand, OIL is the logarithm of the real price of oil (the price of Brent crude measured in national currency and deflated by the GDP deflator), $Y$ is the logarithm of real GDP per capita measured in 2005 USD PPP, $\beta_{i}$ is the country fixed effect and $X$ is a set of country-specific variables (such as the unemployment rate, population density, the old age dependency ratio, and the level of urbanisation).

The estimates show that the share of smaller cars in total demand depends positively on the level of real oil prices, meaning that consumers tend to buy a smaller car when oil prices are high (Table 2, specification 1). This result is in line with the literature which finds that the oil prices influence the type of car that households purchase (Klier and Linn, 2010; Gillingham, 2011; Knittel and Sandler, 2010). ${ }^{2}$ The level of GDP per capita does not influence the size of cars (Table 2, specification 3 and 4), but GDP per capita growth plays a role in the short run, with consumers buying smaller cars during economic downturns (specifications 1 to 4 ).

Using GDP per capita and oil price projections from the spring-2013 OECD Economic Outlook shows that the share of small cars is likely to increase significantly in most countries over the next eight years. The average share in the OECD is projected to rise by 5 percentage points (from $53 \%$ in 2012 to $58 \%$ in 2020). 


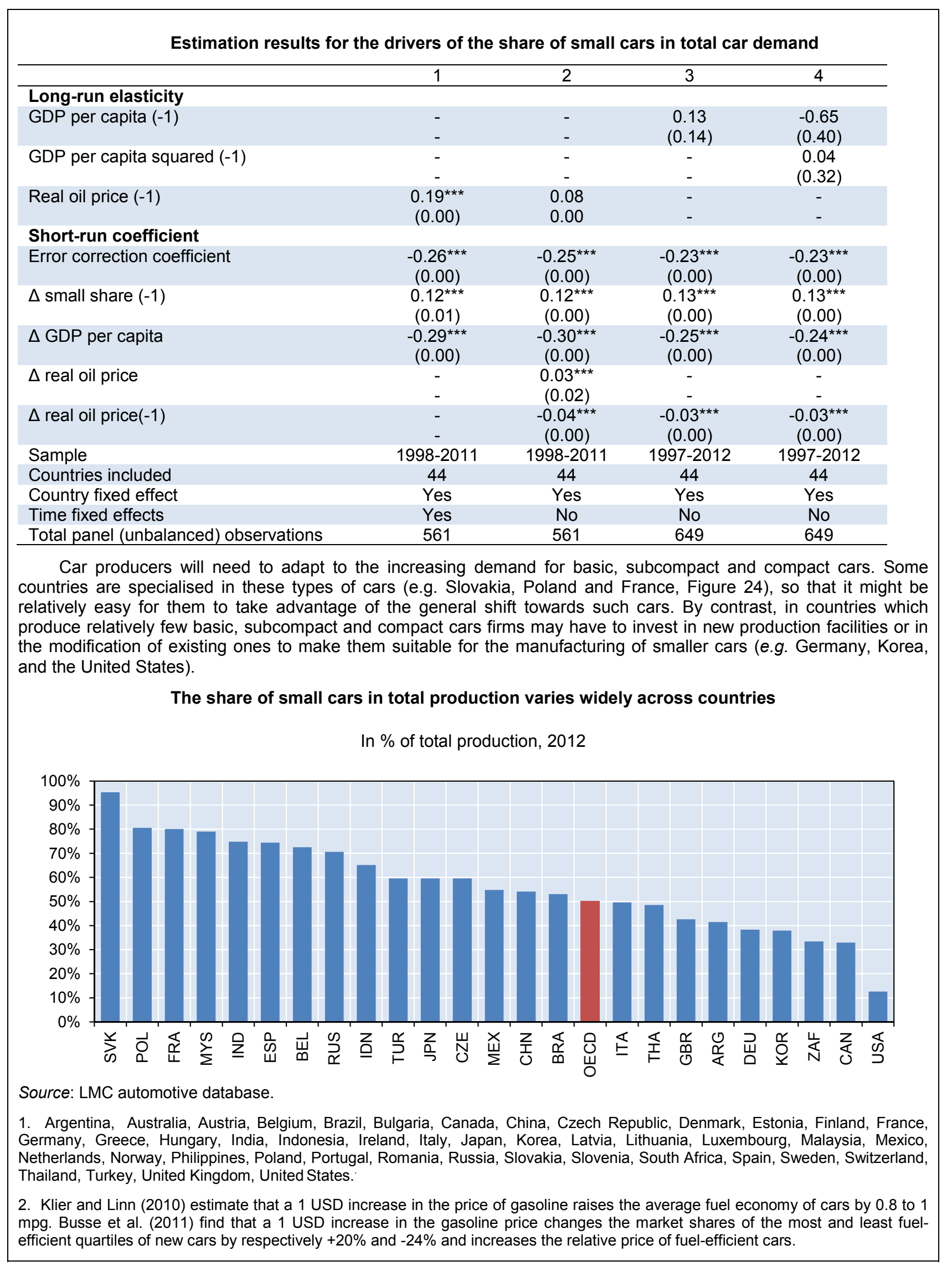




\section{Conclusions}

37. The analysis conducted above suggests that the projected pick-up in economic activity in OECD countries to growth rates that are closer to historical norms will not be sufficient to absorb the current large overcapacities observed in a number of European countries. In these countries, clearing excess capacity may thus require either to increase the share of domestic cars sold in both foreign and domestic markets or to downsize production capacities.

- To increase demand for domestically produced cars, countries with overcapacity could divert demand from their competitors by improving their relative competitiveness. They could also specialise in the market segments which are set to grow strongly in the future, in particular if their overcapacity issues are due to a mismatch between the cars they currently produce and the cars demanded by consumers. The projections suggest, however, that even a strong increase in export market shares, while welcome, might not be sufficient to clear existing excess capacity.

- In absence of a sustained improvement in demand prospects, car producers might have to downsize production capacity. Such structural adjustments are likely to take time because under uncertainty, there is a value for car producers of waiting before downsizing. For instance, car makers might delay downsizing if they expect that competitors will also reduce capacities in the near future. Downsizing non-viable firms is likely to generate long-term benefits by improving the allocation of resources in the economy, but may also induce social costs. Because the automobile sector is geographically concentrated, plant closures might significantly damage the local economy as upstream activities could also leave affected regions. The US automobile industry has gone through a major restructuring with the support of the US and Canadian governments (Box 2). Capacity of the three main US car producers was reduced by $29 \%$ between 2004 and 2012 (McAlinden and Chen, 2012). This restructuring has helped to restore profitability and price competitiveness of domestic producers (Klier and Rubenstein, 2013). However, employment in the automotive sector did not recover as fast as production and stands around $20 \%$ below its pre-crisis level.

38. Subsidising car purchases through various mechanisms has often been used as means to boost car demand and support the domestic automobile industry. However, not least because such policy has only temporary effects on car demand, it is not appropriate to deal with structural overcapacity. Car scrapping schemes may curb long-term growth by delaying the necessary adjustments to structural changes in the automobile industry and lock in inefficient activities. Temporarily increasing demand for firms that are possibly not viable might divert private investment from more profitable activities, thereby distorting the allocation of resources in the economy. Furthermore, even in the short term, car scrapping schemes may have a limited impact on activity as they only shift car consumption in time (Haugh et al., 2010).

\section{Box 2. The restructuring of the US car industry}

In 2008, due to a strong decline in car sales, a high level of liabilities and scarce availability of credit, two out of the "Big Three" US automakers - General Motors Corporation (GM) and Chrysler - encountered major cash shortages and had to seek government assistance. The US and Canadian governments first provided the two companies with emergency loans under a number of conditions, including the provision of credible restructuring plans aiming at restoring the profitability of the firms. The US government then appointed a task force on the automobile sector involving industry experts and financial advisors - to devise a strategy for dealing with GM and Chrysler and evaluate their long-term viability, in particular as regard the plans they had drawn up. The latter were considered as insufficient and the government decided to not provide further loans. Instead, it proposed to restructure both GM and Chrysler through short and managed bankruptcies. After failing to find an agreement with their stakeholders on the management of their debts, GM and Chrysler underwent Chapter 11 bankruptcy procedures in Spring 2009. ${ }^{1}$ Viable assets of the automakers were sold to new "General Motors" and new "Chrysler" companies which were partially owned by the government. ${ }^{2}$ 
Further measures were put in place to support the restructuring of the US automobile industry. The government implemented the "Auto Supplier Support Program" in March 2009 to ensure that GM and Chrysler's suppliers were paid, to keep access to credit, and thus to maintain their activities. The "Warranty Support Program" was created to backstop the two car makers' warranties, thereby encouraging consumer to continue buying GM and Chrysler cars during the restructuring period. A "cash for clunkers" program was also introduced in summer 2009 for three months to stimulate car demand. In addition, a White House Council on Automotive Communities was established to assist communities affected by the restructuring of the automobile industry.

The government provided financial support to the two carmakers on the condition that they largely restructure their activities and commit to plans to return to viability. This induced major changes in the US car industry. For instance, GM was required to cut excess capacities, streamline its brands, and invest in the production of a small and energy efficient car. As a result, 13 out of 47 assembly and part plants were shut down, several brands (Hummer, Saturn, Saab, and Pontiac) were sold or discontinued, the number of dealerships was reduced from 6000 to 3600 and the workforce was cut from 80000 employees in 2009 to 49000 in 2012. Bargained union contracts were also deeply renegotiated. With the 2009 labour agreement, GM was notably allowed to expand the use of entry-level 'Tier 2' workers (paid around half the hourly cost of a 'Tier 1' worker), to suspend the cost-of-living adjustments and performance bonuses of 'Tier 1' workers, to reduce paid time off and place restrictions on overtime. The Jobs Bank - a programme that paid idle workers a large share of their wage until they were appointed to a new position - was terminated and compensation and retiree health care benefits were reduced.

The bailout effectively supported the US car industry (Klier and Rubenstein, 2013). Together with the rebound in car demand driven by the economic recovery, the Chrysler and GM restructuring contributed to reduce excess capacity. After reaching a record low in January 2009 (at around 30\%), capacity utilisation in the car industry recovered to above the OECD average in 2012 (above 80\%). After their restructuring, the two companies rapidly became profitable and gained market shares (the first time on the US market since 1995). Nevertheless, analysts point to some remaining challenges including the relatively high healthcare and pension costs which may weigh on competitiveness of the two carmakers relative to foreign-owned competitors.

The use of public funds - in particular the Troubled Asset Relief Program, initially dedicated to financial firms to support the car industry is still controversial, however. The State intervention was justified by the risk that a sudden and disordered bankruptcy of the two companies would have deteriorated significantly and permanently the US economy. The failure of GM and Chrysler was estimated to result in a loss of around 1 million jobs (White House Office of the Press Secretary, 2008). The bailout eliminated this risk, but, as pointed out by the congressional oversight panel in charge of evaluating the government intervention, it might also have created moral hazard, by providing an implicit government guarantee to large US firms (Congressional Oversight Panel, 2011). Besides, the overall impact of the government intervention on public finances is difficult to evaluate. At the beginning of the year, the US Treasury estimated the net direct cost of the bailout at around USD 20.3 billion out of the total USD 80 billion spent by the government. ${ }^{3}$ Some evaluations suggest that the cost of the GM and Chrysler liquidations would have exceeded the cost of the bailout, notably because of the increase in transfer payments and reduction in tax revenues that the failure of the two companies might have induced (CAR, 2010; Scott, 2010). ${ }^{4}$

1. Chapter 11 is a form of bankruptcy procedure that allows a debtor to reorganise its business affairs and assets, providing some time and tools to restructure the debt.

2. The US and Canadian governments owned around $9.8 \%$ and $2.5 \%$ of the "new" Chrysler equity respectively. The share of equity owned by both governments was significantly higher for the "new" General Motors company, amounting to respectively $60.8 \%$ and $11.7 \%$. Since 2009 , the US government has progressively sold its share in the two companies fully for Chrysler and partly for General Motors (Canis and Webel, 2013).

3. Chrysler's bailout is estimated to have cost USD 1.3 billion, but the net impact of the GM bailout is unknown as the government has not yet fully sold its share in the company. The White House recently announced that the bailout cost might be reduced to USD 14 billion.

4. For instance, the net impact on government income of the State intervention - compared with a scenario in which both companies failed - is estimated at around 22 billion in 2009 and 7 billion in 2010 (CAR, 2010). 


\section{REFERENCES}

Bagnoli, P., E. Rusticelli and D. Turner (2013), "A Review of Alternative Concepts of Trend Output Incorporating Macroeconomic Imbalance Indicators" OECD Economics Department Working Papers, forthcoming.

Busse M., C. Knittel, F. Zettelmeyer, (2011) "Pain at the Pump: The Differential Effect of Gasoline Prices on New and Used Automobile Markets", Working Paper, MIT.

Canis, B. and B. Webel, (2013) "The Role of Tarp Assistance in the Restructuring Of General Motors", Report No. R41978, CRS Report for Congress, Washington, DC: Congressional Research Service.

Capgemini (2011), "Changing Dynamics Drive New Developments in Technology and Business Models Cars Online 11/12".

Capgemini (2013), "My Car, My Way - Cars online12/13”.

CAR (2010), "The Impact on the US Economy of the Successful Automaker Bankruptcies", Center for Automotive Research.

Chamon, M., P. Mauro and Y. Okawa (2010), "Mass Car Ownership in the Emerging Market Giants", Econ Policy, No. 23 (2008), pp. 245-296.

Congressional Oversight Panel (2011), March Oversight Report: The Final Report of the Congressional Oversight Panel, Report No. 64832, Washington, DC: Congressional Research Service.

Cooper A., Chen Y. and S. McAlinden (2010), "The Economic and Fiscal Contributions of the Cash for Clunkers Program: National and State Effects", CAR Research Memorandum, Center for Automotive Research.

Edelstein, P. and L. Kilian (2009), "How Sensitive are Consumer Expenditures to Retail Energy Prices", Journal of Monetary Economics, No. 56, pp.766-779.

Eskeland, G.S. and T.N. Feyzioglu (1997), "Is Demand for Polluting Goods Manageable? An Econometric Study of Car Ownership and Use in Mexico", Journal of Development Economics, No. 53 (2), pp. $423-445$.

Gillingham, K. (2011), "How Do Consumers Respond to Gasoline Price Shocks? Heterogeneity in Vehicle Choice and Driving Behavior", Working Paper, Yale University.

Goldberg, P.K. (1998), "The Effects of the Corporate Average Fuel Efficiency Standards in the U.S.", Journal of Industrial Economics, No. 46, pp. 1-33.

Goodwin, P., J. Dargay and M. Hanly (2004), "Elasticities of Road Traffic and Fuel Consumption with Respect to Price and Income: A Review", Transport Reviews, No. 24 (3), pp. 275-292.

Graham, D.J. and S. Glaister (2004), "Road Traffic Demand Elasticity Estimates: A Review", Transport Reviews, No. 24 (3), pp. 261-274.

Hassler J. (2001), "Uncertainty and the Timing of Automobile Purchases", Scandinavian Journal of Economics, No. 103(2), pp. 351-366. 
Haugh, D., A. Mourougane and O. Chatal (2010), "The Automobile Industry in and Beyond the Crisis", OECD Economics Department Working Papers, No. 745, OECD Publishing.

Hughes J., C. Knittel and D. Sperling, "Evidence of a Shift in the Short-Run Price Elasticity of Gasoline Demand", The Energy Journal, No. 29 (1) (2008), pp. 93-114.

INSEE (2009), Note de Conjoncture, INSEE, Mars 2009.

Klier T., and J. Linn (2010), "The Price of Gasoline and New Vehicle Fuel Economy: Evidence from Monthly Sales Data", American Economic Journal: Economic Policy, No. 2(3) pp. 134-5.

Klier T. and J.M. Rubenstein (2013), "Restructuring of the U.S. Auto Industry in the 2008-2009 Recession”, Economic Development Quarterly, Vol. 27, No. 2, pp. 144-159.

Knittel, C. R. and R. Sandler (2010), "Carbon Prices and Automobile Greenhouse Gas Emissions: The Extensive and Intensive Margins”, NBER Working Papers, No. 16482, 2010.

KPMG (2012), "Overcapacity: A Potential 'Speed Bump' in the World's Largest Automotive Market", KPMG Global China Practice.

KPMG (2013), KPMG's Global Automotive Executive Wurvey 2013.

McAlinden, S.P. and Y. Chen (2012), "After the Bailout: Future Prospects for the US Auto Industry", Center for Automotive Research.

Mehlin, M., C. Vance, A. Guehnermann, S. Buchheim (2004), "Preparation of the 2003 Review of the Commitment of Car Manufacturers to Reduce $\mathrm{CO}_{2}$ Emissions from M1 Vehicles", Final Report of Task A: "Identifying and Assessing the Reasons for the $\mathrm{CO}_{2}$ Reductions Achieved between 1995 and 2003" to the European Commission, German Aerospace Centre (DLR), Berlin.

Meyer I., M. Leimbach, C.C. Jaeger (2007), "International Passenger Transport and Climate Change: A Sector Analysis in Car Demand and Associated $\mathrm{CO}_{2}$ Emissions from 2000 to 2050", Energy Policy, No. 35, pp. 6332-6345.

Nielsen (2013), "In China's Auto Market, Smaller Cities are in the Driver's Seat”.

OECD (2013), Trade in Value-Added, Country Notes, OECD Publishing.

Ryan L., S. Ferreira and F. Convery (2009), "The Impact of Fiscal and Other Measures on New Passenger Car Sales and CO2 Emissions Intensity: Evidence from Europe", Energy Economics, No. 31(3), pp. 365-374.

Scott, R. (2010), "Huge Return on Taxpayer Investment - Benefits of the Auto Restructuring Plan Vastly Exceeded the Costs", Economic Policy Institute, Issue Brief, No. 290.

Smith, B. and Y. Chen (2009), "The Major Determinants of U.S. Automotive Demand: Factors Driving the U.S. Automotive Market and Their Implications for Specialty Equipment and Performance Aftermarket Suppliers", CAR, Center for Automotive Research.

White House Office of the Press Secretary (2008), Fact Sheet: Financing Assistance to Facilitate the Restructuring of Auto Manufacturers to Attain Financial Viability, Dec. 19. 
ECO/WKP(2013)89

\section{WORKING PAPERS}

The full series of Economics Department Working Papers can be consulted at www.oecd.org/eco/workingpapers/

1096. Environmental policies and productivity growth - a critical review of empirical findings

(November 2013) by Tomasz Koźluk and Vera Zipperer

1095. Green growth challenges and the need for an energy reform in Mexico

(November 2013) by Carla Valdivia de Richter

1094. From bricks to brains: increasing the contribution of knowledge-based capital to growth in Ireland

(November 2013) by David Haugh

1093. China's march to prosperity: reforms to avoid the middle-income trap

(November 2013) by Vincent Koen, Richard Herd and Sam Hill

1092. Multi factor productivity with natural capital

(November 2013) by Nicola Brandt, Paul Schreyer and Vera Zipperer

1091. Growth-promoting policies and macroeconomic stability (forthcoming)

(October 2013) by Douglas Sutherland and Peter Hoeller

1090. Policies for inclusive urbanisation in China

(October 2013) by Vincent Koen, Richard Herd, Xiao Wang and Thomas Chalaux

1089. Fiscal devaluation - can it help to boost competitiveness?

(October 2013) by Isabell Koske

1088. How to achieve growth- and equity-friendly fiscal consolidation? A proposed methodology for instrument choice with an illustrative application to OECD countries

(October 2013) by Boris Cournède, Antoine Goujard and Álvaro Pina

1087. Improving school-to-work transition in New Zealand

(September 2013) by Alexandra Bibbee

1086. The agri-food situation and policies in Switzerland

(September 2013) by Peter Jarrett and Charlotte Moeser

1085. Japan's challenging debt dynamics

(August 2013) by Yvan Guillemette and Jan Strasky

1084. Transitions in and out of unemployment among young people in the Irish recession

(August 2013) by Elish Kelly, Seamus McGuinness, Philip O'Connell, David Haugh and Alberto González Pandiella

1083. Is there convergence of Russia's regions? Exploring the empirical evidence: 1995-2010

(August 2013) by Hartmut Lehmann and Maria Giulia Silvagni

1082. The benefits and costs of highly expansionary monetary policy

(August 2013) by Łukasz Rawdanowicz, Romain Bouis and Shingo Watanabe 
1081. The effectiveness of monetary policy since the onset of the financial crisis

(August 2013) by Romain Bouis, Łukasz Rawdanowicz, Jean-Paul Renne, Shingo Watanabe and Ane Kathrine Christensen

1080. Responding to key well-being challenges in Austria

(August 2013) by Rauf Gönenç, Oliver Röhn, Christian Beer and Andreas Wörgötter

1079. Austria's well-being goes beyond GDP

(August 2013) by Oliver Röhn, Rauf Gönenç, Christian Beer and Romina Boarini

1078. Improving fiscal federal relations for a stronger Mexico

(August 2013) by Aida Caldera Sánchez

1077. Deleveraging: challenges, progress and policies

(August 2013) by Romain Bouis, Ane Kathrine Christensen and Boris Cournède

1076. Policies to support sustainable long-term growth in New Zealand

(July 2013) by Calista Cheung

1075. Do structural policies affect macroeconomic stability?

(July 2013) by Volker Ziemann

1074. A simple fiscal stress testing model - case studies of Austrian, Czech and German economies (July 2013) by Ondra Kamenik, Zdenek Tuma, David Vavra and Zuzana Smidova

1073. Road connectivity and the border effect: evidence from Europe

(July 2013) by Henrik Braconier and Mauro Pisu

1072. Fiscal consolidation across government levels. Part 3: Intergovernmental grants, pro- or counter-cyclical?

(July 2013) by Hansjörg Blöchliger and Balázs Égert

1071. Fiscal consolidation across government levels. Part 2: Fiscal rules for sub-central governments, update of the institutional indicator

(July 2013) by Kaja Fredriksen

1070. Fiscal consolidation across government levels. Part 1: How much, what policies?

(July 2013) by Hansjörg Blöchliger

1069. Restructuring the electricity sector and promoting green growth in Japan

(June 2013) by Randall S. Jones and Myungkyoo Kim 